\section{Resseguro e Capital de Solvência: Atenuantes da Probabilidade de Ruína de Seguradoras}

\author{
Reinsurance and Solvency Capital: Mitigating Insurance Companies' Ruin \\ Probability
}

\section{RESUMO}

Contexto: seguradoras são importantes à sociedade, uma vez que garantem proteçáo financeira aos indivíduos contra perdas patrimoniais, além de fomentarem o mercado de capitais por meio da alocaçáo de ativos garantidores. Assim, é fundamental avaliar os instrumentos que garantam sua solvência financeira de longo prazo. Dentre eles estáo a adoção de tratados de resseguro, alocação de capital de solvência e modelagem atuarial dos processos de risco. Objetivo: estimar a probabilidade de ruína em processos de risco com a adoção de contratos de resseguro (quota-parte e excesso de danos), comparativamente a cenários sem tais tratados. Métodos: simulou-se o processo de CramérLundberg via método de Monte Carlo, ajustando diversas distribuiçóes probabilísticas à severidade do processo de Poisson composto, calibrando um conjunto de 3.917.863 microdados reais, segregados em 30 ramos securitários. Resultados: ainda que cada ramo apresente particularidades na severidade do sinistro, a correta escolha de resseguro (proporcional ou não) implica a reduçáo da probabilidade de ruína para um capital de solvência fixo. Conclusáo: a escolha adequada do contrato de resseguro, especialmente quando há evidências de elevada curtose nos valores de sinistros, intensifica o decaimento exponencial da relaçáo entre o capital de solvência e a probabilidade de ruína.

Palavras-chave: processos de risco; resseguro; capital de solvência; probabilidade de ruína.
* Autor Correspondente.
1. Universidade de São Paulo, Faculdade de Economia, Administração, Contabilidade e Atuária, São Paulo, SP, Brasil.

Como citar: Euphasio Junior, J. W., \& Carvalho, J. V. F. (2022). Resseguro e capital de solvência: Atenuantes da probabilidade de ruína de seguradoras. Revista de Administração Contemporânea, 26(1), e200191. https://doi.org/10.1590/1982-7849rac2022200191.por

\section{ABSTRACT}

Context: insurance companies are important to society, since they guarantee financial protection to individuals from property losses, in addition to fostering the capital market through the allocation of guarantee assets. Thus, it is essential to evaluate the instruments that guarantee their long-term financial solvency. Among them are the adoption of reinsurance treaties, the sizing of the solvency capital, and the actuarial modeling of risk processes, which allow the measurement of the ruin probability. Objective: estimate the ruin probability in risk processes with the adoption of reinsurance contracts (quota share and excess of loss), compared to scenarios without such treaties. Methods: the Cramér-Lundberg process was simulated using the Monte Carlo method, adjusting several probabilistic distributions to the severity of the compound Poisson process, which is calibrated with a set of 3,917,863 real microdata, from 30 insurance lines of business. Results: it was found that, although each branch presents particularities in the claim severity, the correct choice of reinsurance (proportional or not) implies the reduction of the ruin probability for a fixed solvency capital. Conclusion: the appropriate choice of the reinsurance contract, especially when there is evidence of high kurtosis in the claim values, intensifies the exponential decline in the relationship between the solvency capital and the ruin probability.

Keywords: risk processes; reinsurance; solvency capital; ruin probability.

\begin{tabular}{|c|c|c|c|c|c|c|c|c|c|}
\hline & 1 & 2 & 3 & 4 & 5 & 6 & 7 & 8 & 9 \\
\hline $1^{a}$ rodada & (x) & $\stackrel{8}{=}$ & $\stackrel{5}{6}$ & $x$ & & & & & \\
\hline a rodada & $\stackrel{8}{2}$ & & & & & & & & \\
\hline
\end{tabular}




\section{INTRODUÇÃO}

O segmento de seguros torna-se cada vez mais importante na economia brasileira, pois sua participação no PIB passou de 2,59\% em 2003 para 3,82\% em 2016 (R\$ 239,4 bilhóes), segundo relatório oficial da Superintendência de Seguros Privados - Susep (Superintendência de Seguros Privados [SUSEP], 2018). Neste período, as receitas anuais das seguradoras cresceram à taxa real anual média de $16,60 \%$, mais do que a economia brasileira, que cresceu à taxa real anual média de 4,14\%.

$\mathrm{O}$ contrato de seguro prevê restituição financeira oriunda de eventos adversos que, em caso de materializaçáo, possam acarretar perdas patrimoniais para uma sociedade com interesses legítimos e comuns. Assim, a partir do momento em que se verificam falências de entidades securitárias, indivíduos segurados e beneficiários indicados não receberão as indenizações esperadas em caso de sinistros, gerando uma externalidade negativa que vai além das consequências inerentes ao funcionamento das companhias. Ademais, seguradoras e entidades previdenciárias são investidores institucionais de grande porte, o que pode criar um efeito sistêmico relevante em caso de insolvência.

Neste contexto, o cálculo da probabilidade de ruína torna-se imprescindível, uma vez que ele fornece uma medida do tamanho da exposiçáo de insuficiência de prêmios, bem como da possibilidade de se incorrer em falência em cenários futuros (Baumgartner \& Gatto, 2010). A estimação da probabilidade é fundamental também para o dimensionamento dos montantes requeridos no presente para manter um nível de solvência futura. Para este caso, o acordo Solvency II, análogo ao Basileia III para os bancos, estabelece a obrigatoriedade de constituição de um capital baseado em risco (CBR, ou capital de solvência, CS), para além de um capital-base (CB) regulatório. Estas reservas visam a proporcionar às seguradoras capacidade de cumprir os compromissos assumidos quando da ocorrência de um choque operacional adverso grave, estabelecendo uma probabilidade de insuficiência de capital frente às obrigaçóes de apenas $0,5 \%$, o que garantiria que a ruína não viesse a ocorrer em mais do que uma vez a cada 200 anos, em média (Moro \& Krvavych, 2017).

Visando a garantir convergência aos ditames do Solvency II, a Susep, por meio da resolução CNSP n. ${ }^{\circ}$ $321 / 2015$, dispóe sobre a indispensabilidade de constituição de um capital mínimo requerido (CMR). O CMR constituise no capital total que uma seguradora, entidade aberta de previdência complementar, sociedade de capitalização ou resseguradora local deve manter visando à manutenção das suas operaçôes, sendo igual ao máximo entre o CB (definido por lei, dependendo da natureza jurídica da companhia) e o CBR, montante variável em função dos riscos inerentes à sua operação.

Este CBR, ainda segundo a lei, deve ser segregado de maneira a refletir a exposição aos diversos riscos a que uma companhia está exposta, tais como: capitais baseados em riscos de (a) Subscrição (para cada ramo securitário de atuação da entidade), (b) Crédito (que reflita a exposiçáo a potencial inadimplência junto a resseguradores, cosseguradores e outras contrapartes), (c) Operacional (que dimensione a possibilidade de ocorrência de perdas resultantes de falha, deficiência ou inadequação de processos internos, pessoas e sistemas, ou decorrentes de fraudes ou eventos externos, incluindo o risco legal e excluindo os riscos decorrentes de decisóes estratégicas e à reputação da instituição) e (d) Mercado (possibilidades de perdas resultantes de flutuaçóes dos mercados financeiros, que causam mudanças na avaliação econômica de ativos e passivos).

Ao final, todas essas parcelas apuradas são combinadas por meio de uma forma quadrática e, considerando uma estrutura de dependência estipulada pelo regulador, combinadas em uma só medida (o CMR), que é alocado como patrimônio líquido. Portanto, o dimensionamento correto das reservas de capital deriva de uma estimação consistente da probabilidade de uma seguradora ir à falência.

Neste trabalho, o interesse recai sobre os riscos de subscrição, que são idiossincráticos dos ramos de atividade securitária. Mas para além da constituição de capital baseado em risco de subscrição, o resseguro é outro instrumento de que a seguradora dispóe para reduzir a volatilidade de suas operaçóes, tendo como consequência de sua adoção mudanças nos montantes das reservas. Especificamente no que tange à atenuação da variabilidade dos volumes de indenização, o resseguro atua como principal ferramenta na redução de medidas gerenciais de risco, incluindo diminuição da probabilidade de ruína. A escolha adequada do tratado de resseguro implica o aumento do coeficiente de ajuste, medida representativa de descasamento entre prêmios e sinistros (Bowers, Gerber, Hickman, Jones, \& Nesbitt, 1997). Logo, a empresa estará menos exposta à ruína quanto mais cuidadosa for a escolha do contrato, uma vez que maior será este coeficiente.

Este trabalho tem por objetivo principal estimar a probabilidade de ruína de uma entidade seguradora ao incorporar instrumentos de limitação das garantias contratuais, comparando a cenários sem tais limitadores. Como objetivo secundário, e derivado diretamente do primeiro, dimensionar o capital de solvência associado a riscos de subscrição. Define-se probabilidade de ruína como a frequência esperada de vezes em que a seguradora teria decretado falência em cenários futuros. Por ruína entendese o estado que decorre de uma reserva de capital ser 
integralmente consumida depois de efetuadas as operaçóes gerenciais de receitas e despesas.

Utilizam-se dados reais fornecidos por uma seguradora (transformados para a manutenção de seu sigilo) com o propósito de avaliar numericamente os resultados obtidos. A partir dessas informaçôes, serão simulados processos de risco, dos quais serão calculadas as respectivas probabilidades de ruína. Depois, a comparação será feita com a presença de resseguro, em que serão considerados os contratos proporcionais e de excesso de danos, visando a mensurar não somente os impactos da adoção desta ferramenta na probabilidade de ruína, mas também os efeitos da escolha por diferentes tipos de contratos, considerando as distintas dinâmicas das carteiras.

\section{FUNDAMENTAÇÃO TEÓRICA E LITERATURA EMPÍRICA}

\section{Contratos de resseguro e sua estrutura}

Alinhado a Bowers, Gerber, Hickman, Jones e Nesbitt (1997), o tratado de resseguro é um contrato acordado pelo segurador (cedente) junto a uma resseguradora, de maneira a transferir a ela o ônus da cobertura financeira de eventos contingentes (extremos ou não). Uma das funções do resseguro é proteger o balanço patrimonial da seguradora pela ocorrência das seguintes configuraçôes: (a) acumulação de sinistros de muitas apólices afetadas pelo mesmo evento; (b) sinistros graves; ou (c) sinistro agregado de uma carteira ir muito além do esperado. Todas essas situaçóes indesejadas, na ausência de proteção do resseguro, podem causar a falência da seguradora, que é responsável direta pela indenização ao segurado.

Assim, é mediante a adoção do tratado de resseguro que a cedente cobre os sinistros extremos, permitindo à companhia elevar a sua subscrição bruta para além do nível de retenção definido pelas normas vigentes, porém, respeitando-as sob a ótica da subscrição líquida. Esse limite de retenção (LR), definido pela seguradora, é uma função do patrimônio líquido contábil e impóe uma restrição à capacidade operacional na subscrição de novos contratos de seguro. Logo, em processos de risco, o tipo de contrato de resseguro adotado impacta diretamente na estimação da probabilidade de ruína, uma vez que a sua estrutura refletirá tanto na expectativa como na variabilidade das indenizaçóes.

Segundo Deelstra e Plantin (2014), os tratados de resseguro podem ser classificados como resseguros proporcionais (dentre os quais destacam-se o quota-parte e o excedente de responsabilidade) ou náo proporcionais (os principais são excesso de danos por risco, excesso de danos por evento, excesso de dano catastrófico e stop-loss).
Neste trabalho, será avaliado apenas um de cada categoria: quota-parte e excesso de danos por risco. Seja $X$ uma variável aleatória que denote a severidade associada a uma perda; assim, um contrato de resseguro $h$ é uma transformação na variável aleatória original:

$\left\{\begin{array}{c}\text { 1) } h(X)=\alpha X, \quad 0 \leq \alpha \leq 1(\text { quota }- \text { parte }) \\ \text { 2) } h_{d}(X)=X^{\wedge} d=\min \{X ; d\}(\text { excesso de danos por risco })\end{array}\right.$

A Equação (1) apresenta a formulação matemática para os contratos de resseguro considerados nas simulaçóes propostas, e tem diferentes interpretaçóes, de modo objetivo, em função das suas características. No primeiro caso, $\alpha$ representa a taxa de retençáo incidente sobre o montante do sinistro, que pode ser obtida por meio da divisão do prêmio retido pelo prêmio total. Ou seja, para os contratos proporcionais, as proporçóes de prêmios, como de sinistros, divididas entre a parcela da seguradora e da resseguradora são idênticas, independentemente da magnitude da severidade do sinistro. Como vantagens, esse tratado apresenta fácil implementação, gerenciamento e redução de risco moral, uma vez que seguradora e resseguradora possuem congruência de interesses.

O segundo não satisfaz a mesma taxa de prêmios e sinistros cedidos, ficando uma das partes com uma parcela maior do risco segurado (geralmente, o ressegurador). $\mathrm{O}$ ressegurador intervém somente se o montante do sinistro for superior à prioridade (d) estabelecida. A prioridade define a responsabilidade exclusiva da seguradora, independentemente do valor em excesso a $d$. Em suma, para um contrato não proporcional, a fraçáo de prêmio transferido ao ressegurador não necessariamente é idêntica à razão da indenização de responsabilidade cedida do sinistro.

$\mathrm{Na}$ prática, este limite é dividido em layers (prioridades), que consistem em diferentes níveis de retenção (fixados), facilitando a tarifação dos contratos, pois cada resseguradora pode escolher o grau de sua exposição em cada companhia. Os prêmios dos layers mais altos são maiores, uma vez que estes patamares configuram as caudas das distribuiçóes das seguradoras, e seu pagamento ocorre somente quando uma prioridade muito alta é cruzada. $\mathrm{O}$ desenho operacional do resseguro permite que as seguradoras obtenham uma redução na volatilidade de suas respectivas carteiras (Bowers et al., 1997). Uma vez que tanto a média quanto a variância diminuem, é possível concluir que, para uma mesma probabilidade de ruína, quando da presença de resseguro, é necessário menos reserva inicial.

Bowers et al. (1997) mostram (Teorema 14.5.1) que o resseguro do tipo excesso de danos (ED), sob certas condiçóes, é sempre ótimo quando comparado a um resseguro proporcional, no sentido de maximizar o coeficiente de ajuste, e, portanto, de reduzir a probabilidade 
de ruína. O que o teorema não revela é a magnitude desta redução, principalmente porque o coeficiente de ajuste nunca é diretamente observado. Portanto, eis mais uma contribuição deste trabalho: quantificar os efeitos sobre a probabilidade de ruína e, portanto, no capital de solvência da seguradora.

\section{Revisão da literatura}

A literatura sobre teoria da ruína é extensa e muito relacionada aos desenvolvimentos computacionais, que permitiram avanços nos processos de simulaçáo e métodos numéricos de aproximação. Há diversas maneiras de estimar a probabilidade de ruína. Gatto e Mosimann (2012) exploraram quatro abordagens em processos de risco com Poisson composta. A principal delas é a aproximaçáo via método de Monte Carlo (MMC), simulação estocástica que fornece uma abordagem ao cômputo da probabilidade de ruína. Mais recentemente, Touazi, Benouaret, Aissani e Adjabi (2017) - usando abordagem não paramétrica -, Bareche e Cherfaoui (2019) e Gatto (2020) - estes usando distribuiçóes de cauda pesada - mostraram que as estimativas obtidas pelos métodos de simulação são fortemente estáveis.

Com a evolução das teorias sobre análise de falências e o avanço das técnicas computacionais, foi possível incorporar instrumentos de transferência de risco. Albrecher e Haas (2011) estudaram o comportamento da probabilidade de ruína de uma seguradora que possuía um contrato de resseguro do tipo $\mathrm{ED}$, com prêmios de reintegração. Ao variarem as reintegraçóes e o prêmio cedido (percentual do prêmio total), constataram que um aumento no número de reintegraçôes não necessariamente implica redução proporcional da probabilidade de ruína. Este fato é explicado pela redução do risco (pela expansão da cobertura de resseguro) e simultânea elevação do prêmio de resseguro.

Quando fixado o percentual de prêmio cedido, carregamento de segurança e número de reintegraçóes, os autores identificaram que há uma redução da probabilidade de ruína quanto maior for a reserva inicial, cuja relação dá-se por um decaimento exponencial. Ademais, quando comparado ao cenário-base (sem qualquer tipo de transferência de risco), a inserção de um tratado de resseguro do tipo ED diminui a probabilidade de ir à falência para um mesmo capital inicial, se os carregamentos de segurança da cedente e resseguradora forem semelhantes.

Charpentier (2010) buscou entender a relação entre resseguro, ruína e solvência, atentando para algumas armadilhas que, por falta de uma análise técnica detalhada, podem acarretar aumento da quantidade estimada de falências, contrariamente ao esperado tendo em vista a implementação de um mecanismo de transferência de risco. Sua primeira constatação foi a de que tratados de resseguro do tipo quota-parte não podem aumentar a probabilidade de ruína de uma seguradora, como esperado. Por meio de um exercício numérico, concluiu que o resseguro proporcional, entretanto, pode não ser o mais eficiente na redução da probabilidade de ruína quando os sinistros possuem caudas pesadas.

Para os não proporcionais, em particular para contratos de Excesso de Danos por Risco, a primeira observação é a de que este tipo de tratado é desfavorável quando ocorrem grandes quantidades de sinistros com baixas severidades, portanto, náo ultrapassando a prioridade contratual. Neste cenário, é possível que a probabilidade de ruína aumente mesmo com a presença de resseguro, quando comparada ao cenário sem a presença do resseguro. Charpentier (2010) exemplifica que mudanças sutis no valor do dedutível podem comprometer a solvência da companhia, uma vez que o prêmio líquido decresce mais do que as indenizaçóes líquidas, agravando a probabilidade de ruína. Para um processo de Poisson não homogêneo com dependência entre severidade e frequência de sinistros, a mesma conclusão não intuitiva é obtida: a adoção de resseguro leva a um portfólio mais arriscado.

Imposição de restrições também é objeto de preocupação dos atuários teóricos. Do ponto de vista matemático, Lefèvre, Trufin e Zuyderhoff (2017) mostram que não só a distribuição dos sinistros, mas também a ordenação dos valores de sinistros influencia a avaliação das probabilidades de ruína. Mas não são apenas as ordenaçóes em sinistros que importam: Dickson e Qazvini (2016) avaliam o papel das resseguradoras para minimizar quedas abruptas no patrimônio líquido da seguradora. Já Ramsden e Papaioannou (2019) introduzem ordem sobre o nível de capital, argumentando que a firma poderia tomar empréstimos de terceiros (não apenas seguradoras), em caso de insuficiência do estoque de capital próprio e dificuldade de recapitalizaçáo oriunda da perda de confiança dos acionistas. Neste caso, os autores derivam expressóes explícitas para a função geradora de momentos das injeções acumuladas de capital até o momento de falência, possibilitando estimar a probabilidade de ruína e os pagamentos de dividendos.

A literatura continua desenvolvendo novas abordagens teóricas de aproximação para a estimativa numérica da probabilidade de ruína, focando em modelos mais representativos dos processos de risco do que aqueles baseados em distribuição Poisson composta. Wüthrich (2015) avalia medidas de risco coerentes (como expected shortfall), retornos financeiros e apreçamento do passivo securitário. Cheng, Gao e Wang (2016) usam prêmios estocásticos. Já Tamturk e Utev (2018) usam a mecânica quântica para derivar expressóes para a probabilidade de ruína. 
Curiosamente, apesar da abordagem complexa, os resultados são similares aos da abordagem markoviana.

Alguns autores argumentam que a hipótese de independência entre as ocorrências de sinistros pode não ser realista para certos portfólios (Cheung, Dai, \& Ni, 2018; Eryilmaz \& Gebizlioglu, 2017). Em linha similar, mas impondo estrutura de dependência entre as ocorrências de sinistros de diferentes linhas de negócios, Dong e Wang (2018) usam processos de renovação com retornos financeiros estocásticos para derivar fórmulas assintóticas para a probabilidade de ruína em tempo finito e infinito. Ainda incorporando dependência, há autores que provam como as probabilidades de ruína podem ser afetadas pela estrutura de dependência de cauda entre riscos financeiros e securitários (Chen \& Yuan, 2017; Constantinescu, Kozubowski, \& Qian, 2019; Vidmar, 2018).

$\mathrm{Na}$ literatura brasileira, também se incorporou uma estrutura de dependência entre eventos. Melo (2008) propóe uma aplicação de cópulas de Lévy para a avaliação de um processo multivariado de ruína. Assumiu-se a existência de uma estrutura de dependência entre os sinistros agregados de diferentes linhas de negócios, de modo que alguns ramos subsidiam outros. Conclui-se que a probabilidade de ruína é subestimada se assumida a hipótese de independência nos dados. Assim, ramos compreensivos podem ser os mais sensíveis, porque um evento exógeno pode resultar em sinistros de diferentes coberturas.

Ressalta-se a grande escassez de trabalhos aplicados que se utilizem de microdados reais (Afonso, Cardoso, Reis, $\&$ Guerreiro, 2017), principalmente na literatura nacional. Lemos (2008) testa metodologias clássicas por meio de simulação com distribuiçóes de caudas leves e pesadas. Contudo, não foram incorporadas estruturas de resseguro e seus efeitos nas estimativas para a probabilidade de ruína, e essa é a lacuna que se pretende preencher.

Finalmente, é importante destacar que o presente trabalho é um dos raros casos - mesmo no contexto internacional - em que são utilizados microdados reais, respeitando as peculiaridades de cada ramo securitário, para obter estimativas precisas da probabilidade de ruína. Tratase de contribuiçáo efetiva para a produçáo de conhecimento científico nacional sobre a modelagem de estratégias de gerenciamento de riscos securitários.

\section{MÉTODO}

\section{processo de Cramér-Lundberg}

Para o cálculo da probabilidade de ruína será simulado o processo de risco de Cramér-Lundberg, que pode ser entendido como um modelo estocástico que mede as variações do patrimônio líquido de uma companhia seguradora temporalmente. A estrutura deste processo é:

$$
U_{t}=U_{t-1}+P_{t}-S_{t},
$$

para todo $t>0$ e de tal forma que $U_{0}$ seja o capital inicial (ou reservas livres, não negativo) da entidade securitária, $P_{t}=(1+\theta) \mathbb{E}\left[S_{t}\right]$ são os prêmios agregados arrecadados no instante $t, \theta>0$, o carregamento de segurança e $S_{t}$ o sinistro agregado no mesmo instante de tempo $t$ definido como uma soma aleatória de variáveis aleatórias:

$$
S_{t}=X_{1}+X_{2}+X_{3}+\ldots+X_{N(t)}
$$

em que $N(t)$ representa a quantidade de sinistros ocorridos em $t$ e $X_{i}, \forall i=1, \ldots, n$, variáveis aleatórias independentes e identicamente distribuídas não negativas, com $\mathbb{P}\left[X_{i}>0\right]=p$, independentes de $N(t)=n, \forall n \in \mathbb{R}_{+}$, representando a severidade individual de cada sinistro. Logo, o $S_{t}$ é uma convolução entre frequência e severidade das indenizaçóes. Destaca-se, por fim, que todas as variáveis aleatórias que regem o processo de risco (i.e., tanto os geradores da frequência como da severidade de cada um dos ramos) são invariantes no tempo.

Exatamente porque as variáveis de entrada do processo de risco definido pela Equaçáo (2) regem a dinâmica da operação precípua de uma seguradora, i.e., a arrecadação de prêmios e pagamento de sinistros, o modelo de CramérLundberg é apropriado para mensurar apenas o CBR de subscrição. Todas as demais parcelas possuem metodologias próprias para seus dimensionamentos.

Definição (probabilidade de ruína). Ocorre ruina se o processo de risco definido pela Equação (2) atingiu um valor negativo. A probabilidade de ruina é uma medida deste evento, tal que:

$$
\psi\left(U_{0}\right)=\mathbb{P}\left[U_{t}<0 \mid U_{0}\right]
$$

A partir do desenvolvimento temporal, define-se o tempo até ruína como:

$$
T=\left\{\begin{array}{c}
\inf \left\{t>0: U_{t}<0\right\}, \text { se este ínfimo existir }, \\
\infty, \text { caso contrário. }
\end{array}\right.
$$

Portanto, trata-se do primeiro instante de tempo em que a seguradora é decretada falida. A probabilidade de ruína também pode ser expressa por $\psi\left(U_{0}\right)=\mathbb{P}\left[T<\infty \mid U_{0}\right]$. Assim, é evidente que o balanço patrimonial possui uma perspectiva estatísticoatuarial. Entre os requerimentos de capital que compóem o balanço de uma seguradora, têm-se as provisóes técnicas, obtidas por meio da esperança do sinistro agregado. Como estas provisões técnicas são carregadas por $\theta$, temse a margem de prudência das provisóes técnicas. Ainda na 
escala do passivo, adicionalmente à margem de prudência, o capital de solvência $\left(U_{0}\right)$ compóe o patrimônio líquido da entidade.

O desconhecimento da verdadeira distribuição do sinistroagregado implica odesconhecimentodaprobabilidade de ruína. Logo, todas essas contas contábeis são variáveis aleatórias que possuem média e variância, evidenciando que parcela expressiva e relevante do balanço patrimonial de uma seguradora é dotada de incerteza. Portanto, caso o funcional esteja dimensionado incorretamente, o balanço patrimonial não refletirá adequadamente as informaçóes mais fidedignas a respeito de sua situação financeira.

\section{Procedimento de simulação}

Nesta seção são detalhados os procedimentos de ajustes/simulaçóes, visando a obter estimativas das probabilidades de ruína. A primeira etapa consistirá na segregaçáo da base de microdados, segundo enquadramento de cada apólice na codificação dos ramos Susep. Esta separação é necessária porque cada ramo possui uma dinâmica própria de ocorrência de sinistros, exigindo adoção de diferentes distribuiçóes probabilísticas, tanto na frequência como na severidade.

$\mathrm{Na}$ segunda etapa serão estimadas as distribuições da severidade de cada ramo, com o objetivo de (a) computar as convoluçóes de cada ramo pela Equação (3) e (b) dimensionar os prêmios correspondentes de cada ramo. Assim, será possível avaliar a dinâmica da quantidade total de segurados presentes no portfólio de cada ramo, bem como a quantidade histórica de apólices que incorrem em sinistros. Enquanto a primeira quantidade formará o volume de prêmios pagos à seguradora, a segunda frequência representa o $N(t)$ da Equação (3).

Uma vez realizadas essas duas etapas, será utilizado o MMC para o desenvolvimento das simulaçóes do processo dado pela Equação (2), de maneira que elas sejam obtidas. Segundo Coulibaly e Lefèvre (2008), o MMC é comumente utilizado para simular problemas que podem ser representados por processos estocásticos. A implementação deste método não assegura a obtenção da solução exata; entretanto, com o aumento das iteraçóes é possível alcançar estimativas precisas do verdadeiro valor à medida que um número suficientemente grande de simulaçóes é processado (Gatto \& Mosimann, 2012). Além disso, pelo MMC há a criação de amplo espectro de possíveis cenários aleatórios a partir de calibração dos parâmetros ajustados (Mikosch \& Samorodnitsky, 2000; Touazi, Benouaret, Aissani, \& Adjabi, 2017).

Serão consideradas como cenário-base as operações contratuais de receitas e despesas da seguradora sem incorporar instrumentos de limitação das garantias contratuais (resseguro). Assim, a técnica consistirá em repetir as simulaçóes, para cada ramo, 100 mil vezes, de modo a reproduzir as trajetórias futuras da realização do processo de risco definido pela Equação (2). Pela Lei dos Grandes Números (Baumgartner \& Gatto, 2010), se o número de iteraçôes for suficientemente grande é possível garantir convergência entre as estatísticas simuladas e os respectivos valores reais do funcional. Uma vez efetuado este procedimento, o estimador da probabilidade de ruína $(\hat{\psi})$ é:

$$
\hat{\psi}_{s}\left(U_{0}\right)=\frac{\#\left(U_{t}<0: \text { para algum } t>0\right)}{r}
$$

em que $s$ é o ramo Susep considerado e $r$ a quantidade de replicaçóes/simulaçóes do processo. Adicionalmente, tanto para as análises destinadas ao cenário-base como para os modificados (descritos a seguir) serão feitas variaçóes sobre $U_{0}$, com o intuito de dimensionar o capital de solvência de cada ramo.

Dispondo dos resultados do cenário-base, o passo seguinte consiste em incorporar nas distribuiçóes probabilísticas dos sinistros os instrumentos de resseguro definidos pela Equação (1), inclusive variando o tamanho da prioridade e do quota-parte. Estas modificaçôes possibilitarão observar os efeitos que os mecanismos de transferência de riscos promovem na solvência, atentando-se para a variabilidade dos montantes de indenização, estabilidade de resultado e relaçáo de decaimento exponencial entre capital inicial e probabilidade de ruína.

\section{A base de dados}

A base de dados utilizada contém 3.917.863 apólices, segregadas em 30 ramos Susep, com as suas respectivas emissões efetuadas em algum momento entre 01/01/2015 e 01/05/2018, compreendendo três anos de emissóes e ocorrência de sinistros. A razão da segregação em ramos é porque há variação em relação às condiçôes gerais do contrato, especificidades de risco, cláusulas de exclusão e demais características. Inclusive, padráo de vigência contratual do seguro: cada apólice possui sua própria vigência contratual. Por este motivo, todos os contratos foram trazidos à base de duração anual (caso mais comum no setor), para ser contemplada no modelo de Cramér-Lundberg, processo cujo desenvolvimento dá-se como variaçôes do resultado entre receitas (de prêmios) e despesas (de indenizaçóes), que é original e fundamentalmente baseado no regime de caixa (e, no caso particular deste trabalho, em bases anuais).

Visando a mitigar eventuais disparidades temporais de eventos gerados em regime de competência contábil, todas as informaçóes de prêmios, Provisão de Sinistros a Liquidar (PSL), indenizaçóes pagas e recuperaçóes de resseguro foram anualizadas visando a ajustar a exposição destas apólices. 
Esta opção metodológica é uma hipótese simplificadora, que poderia gerar algum viés nas estimativas. Entretanto, como o tempo médio de duração das 3.917.863 apólices da base é de 327 dias (com desvio padrão de 110 dias), este problema não compromete as estimativas obtidas por MMC em bases anuais, que, como argumentado ao longo do texto, são fortemente estáveis (Bareche \& Cherfaoui, 2019; Gatto, 2020), mitigando eventuais problemas desta natureza. Ademais, como a simulação do processo baseiase em modelagem de risco coletivo, o efeito de apólices individuais está diluído no conjunto padrão do ramo.

Assim, dada uma apólice de $n$ anos de vigência, o prêmio pago pelo segurado foi divido por $n$, de forma que a parcela do prêmio corresponde a um ano de cobertura. Este racional também foi aplicado à parcela do sinistro. Portanto, caso esta apólice tenha sinistrado, o valor despendido pela seguradora também foi divido por $n$. Desta forma, a comparação direta entre receitas e despesas, por apólice, torna-se possível, uma vez que ambas as informaçóes estão na mesma base temporal.

Finalmente, destaca-se que os dados originais foram uniformemente transformados para garantir o sigilo da entidade que forneceu os registros, mas mantendo a proporcionalidade entre eles.

\section{As estatísticas descritivas e o ajuste das distribuições de sinistros}

Para o cálculo da severidade individual, somou-se o montante de PSL com os pagamentos realizados até a database de extração dos dados, pois é de interesse o custo total efetivo relacionado a cada apólice. Assim, para os sinistros cuja regulação já tenha sido encerrada, o custo total é igual ao montante de pagamento anualizado, enquanto para os casos pendentes (em aberto) o custo total consiste na soma da provisão (melhor estimativa do desembolso futuro) com o montante de pagamento anualizado até a data-base. Essas informaçóes constam na Tabela 1.

Após realizada a análise da dinâmica de cada ramo quanto à arrecadação de prêmios, frequência de sinistros, valores médios e desvio padrão, respectivamente, o passo seguinte consistiu no ajuste das distribuiçóes probabilísticas de sinistros. Para isto, por ramo Susep, ajustou-se a distribuição mais aderente às características de determinado ramo, bem como os parâmetros associados, uma vez que diferentes ramos podem possuir a mesma distribuição, ainda que com parâmetros diferentes.

As densidades ajustadas foram: Exponencial, Gama, Normal, Log-Normal, Weibull, Weibull Inversa e Pareto, sendo os parâmetros estimados por meio dos métodos da máxima verossimilhança e momentos. $\mathrm{O}$ indicador escolhido para a seleção do melhor modelo foi o critério de informação bayesiano (BIC), buscando seu mínimo.

Nota-se, pela Tabela 2, que há recorrência da Log-Normal, devido ao seu formato assimétrico. Ainda, para os ramos que usualmente possuem maiores curtoses, a distribuição de Pareto se destacou. Ressalta-se que durante a elaboração do trabalho, as distribuiçóes Log-Logística e $t$-Student também foram testadas, sendo elas escolhidas como melhores distribuiçóes para alguns ramos. Todavia, por mais que elas pudessem capturar sinistros de cauda (outliers), tal fato refletia significativamente na geração de sinistros de alta severidade, descolando, por consequência, tanto a média como o montante do sinistro agregado gerado nas simulações. Assim, a escolha final das distribuições levou em conta não somente um indicador puramente estatístico, mas também um backtest qualitativo da capacidade de geração de observações fidedignas dos sinistros reais.

Selecionado o melhor modelo por ramo Susep, o próximo passo consistiu na geração de 10 mil possíveis cenários de sinistro agregado. Para isto, a frequência foi ajustada por uma distribuição Poisson com parâmetro igual à média observada de sinistros na base de dados, bem como a severidade por meio da distribuição escolhida na Tabela 2, com seus respectivos parâmetros por ramo. Visando a dar robustez ao estudo, também se modelou a frequência por meio de uma Binomial Negativa (Pólya Composto); entretanto, este caso gerou observaçóes de sinistros excessivamente maiores do que os números reais, elevando, por conseguinte, o sinistro agregado e a probabilidade de ruína, por ramo. Assim, optou-se por seguir a literatura, rodando as simulaçóes como um processo Poisson composto.

Dada a aleatoriedade na geração do montante dos sinistros, utilizou-se como Limite Máximo de Indenização (LMI) de cada ramo o valor de duas vezes o maior sinistro observado na base de dados, sob o argumento de que a presença de sinistros com valores irreais (porque a seguradora não subscreve riscos desta magnitude) enviesariam a análise final do processo de risco. Portanto, os valores que excediam este LMI foram excluídos do sinistro agregado.

Uma análise de sensibilidade foi realizada, em que se constatou imaterialidade na quantidade de sinistros excluídos, pois, em média, foram deletados apenas $0,37 \%$ dos sinistros gerados nas 10 mil simulaçóes. Esta análise também foi realizada para cenários com cem e mil simulaçóes, que demonstraram um percentual de exclusão, respectivamente, de $0,34 \%$ e $0,37 \%$. Ou seja, aumentar o número de simulaçôes não implica crescimento proporcional do percentual de exclusão, garantindo a viabilidade de sua aplicação no estudo. 
Tabela 1. Estatísticas descritivas da base de dados por ramo Susep.

\begin{tabular}{|c|c|c|c|c|c|c|c|c|c|}
\hline $\begin{array}{l}\text { Ramo } \\
\text { Susep }\end{array}$ & Descrição do ramo & $\begin{array}{c}\text { Quantidade } \\
\text { de apólices }\end{array}$ & $\begin{array}{c}\text { Prêmio } \\
\text { médio }\end{array}$ & $\begin{array}{l}\text { Prêmio } \\
\text { máximo }\end{array}$ & $\begin{array}{l}\text { Prêmio } \\
\text { mínimo }\end{array}$ & $\begin{array}{l}\text { Quantidade } \\
\text { de sinistros }\end{array}$ & $\begin{array}{c}\text { Severidade } \\
\text { média }\end{array}$ & $\begin{array}{c}\text { Severidade } \\
\text { máxima }\end{array}$ & $\begin{array}{c}\text { Severidade } \\
\text { mínima }\end{array}$ \\
\hline 0114 & Compreensivo Residencial & 104.912 & 443 & 201.221 & 23 & 3.665 & 3.170 & 133.009 & 50 \\
\hline 0115 & Roubo & 24.579 & 1.438 & 3.555 .903 & 78 & 1.724 & 14.144 & 5.528 .754 & 50 \\
\hline 0116 & Compreensivo Condomínio & 133.069 & 2.200 & 188.218 & 167 & 15.497 & 7.774 & 3.416 .440 & 22 \\
\hline 0118 & Compreensivo Empresarial & 159.848 & 1.900 & 501.630 & 29 & 9.368 & 13.423 & 6.639 .786 & 40 \\
\hline 0141 & Lucros Cessantes & 3.007 & 40.693 & 22.530 .363 & 78 & 149 & 55.914 & 1.464 .188 & 50 \\
\hline 0167 & Riscos de Engenharia & 1.661 & 20.824 & 2.652 .080 & 278 & 129 & 100.087 & 2.910 .709 & 200 \\
\hline 0171 & Riscos Diversos & 27.554 & 7.481 & 10.250 .780 & 94 & 1.522 & 69.905 & 3.372 .572 & 120 \\
\hline 0196 & $\mathrm{RN}$ e RO & 1.404 & 298.618 & 22.985 .034 & 275 & 226 & 1.985 .611 & 211.148 .985 & 160 \\
\hline 0310 & $\mathrm{D} \& \mathrm{O}$ & 889 & 21.462 & 661.213 & 1.121 & 32 & 145.214 & 725.332 & 5.090 \\
\hline 0351 & R. C. Geral & 14.610 & 14.864 & 8.963 .370 & 19 & 1.123 & 76.978 & 9.132 .978 & 50 \\
\hline 0378 & R. C. Profissional & 2.431 & 21.506 & 2.010 .760 & 224 & 195 & 82.091 & 3.002 .375 & 303 \\
\hline 0520 & APP & 127.018 & 2.286 & 352.673 & 70 & 15.445 & 31.725 & 578.717 & 70 \\
\hline 0531 & Automóvel - Casco & 2.716 .996 & 2.056 & 8.527 .948 & 144 & 209.931 & 10.535 & 1.373 .636 & 21 \\
\hline 0542 & Assistência e Outras Cobert. & 1.101 & 7.461 & 174.011 & 707 & 113 & 23.195 & 172.602 & 165 \\
\hline 0553 & RCFV & 12.698 & 8.213 & 1.903 .616 & 353 & 1.989 & 19.437 & 1.313 .308 & 70 \\
\hline 0622 & Transporte Internacional & 1.374 & 2.558 & 1.968 .857 & 11 & 28 & 10.265 & 90.062 & 22 \\
\hline 0776 & Garantia Segurado - Privado & 750 & 19.484 & 1.428 .468 & 89 & 18 & 54.233 & 180.500 & 100 \\
\hline 0929 & Seguro Funeral & 172 & 2.655 & 12.897 & 124 & 24 & 14.408 & 190.966 & 359 \\
\hline 0982 & AP - Coletivo & 1.078 & 10.496 & 804.270 & 50 & 69 & 42.926 & 346.454 & 80 \\
\hline 0993 & Vida - Pessoas Coletivo & 3.273 & 9.384 & 1.484 .533 & 59 & 279 & 64.837 & 1.294 .180 & 50 \\
\hline 1061 & Habitacional - Prestamista & 41 & 816.594 & 4.872 .770 & 1.750 & 19 & 380.745 & 1.858 .775 & 12.753 \\
\hline 1065 & Habitacional - Demais & 30 & 266.117 & 2.523 .042 & 611 & 12 & 40.799 & 171.917 & 743 \\
\hline 1107 & Florestas sem FESR & 724 & 46.663 & 8.998 .143 & 419 & 37 & 368.361 & 3.144 .258 & 1.903 \\
\hline 1108 & Florestas com FESR & 56 & 16.906 & 163.688 & 978 & 11 & 309.346 & 603.246 & 54.737 \\
\hline 1130 & Benfeitorias e Prod. Agropec. & 33.046 & 3.081 & 1.876 .238 & 33 & 2.052 & 31.989 & 1.275 .627 & 50 \\
\hline 1162 & Penhor Rural & 60.333 & 1.255 & 2.625 .958 & 50 & 1.310 & 30.467 & 1.693 .228 & 119 \\
\hline 1369 & Viagem & 440.742 & 223 & 8.945 & 6 & 8.578 & 4.352 & 590.423 & 27 \\
\hline 1381 & $\mathrm{AP}$ - Individual & 5.650 & 426 & 23.363 & 19 & 80 & 20.321 & 239.264 & 100 \\
\hline 1391 & Vida - Pessoas Individual & 30.252 & 715 & 369.394 & 13 & 85 & 143.205 & 2.053 .441 & 100 \\
\hline 1433 & Marítimos (Casco) & 8.565 & 5.300 & 2.635 .601 & 265 & 252 & 122.024 & 3.782 .900 & 865 \\
\hline
\end{tabular}

Nota. Estatísticas descritivas de todas as apólices ativas (sinistradas ou não) entre jan/2015 e maio/2018. Fonte: elaborado pelos autores, a partir dos microdados cedidos por uma seguradora. 
Tabela 2. Distribuiçôes mais aderentes e seus respectivos parâmetros.

\begin{tabular}{|c|c|c|c|}
\hline Ramo Susep & Distribuição escolhida & Parâmetro 1 & Parâmetro 2 \\
\hline 0114 & Pareto & 3,923732 & $8.971,131000$ \\
\hline 0115 & Log Normal & 7,874931 & 1,633912 \\
\hline 0116 & Log Normal & 7,658535 & 1,676110 \\
\hline 0118 & Pareto & 1,475869 & $5.038,577000$ \\
\hline 0141 & Pareto & 0,612967 & $1.210,940000$ \\
\hline 0167 & Log Normal & 9,473071 & 2,041693 \\
\hline 0171 & Log Normal & 9,756488 & 1,820056 \\
\hline 0196 & Pareto & 0,494173 & $11.990,450000$ \\
\hline 0310 & Weibull Inversa & 0,713026 & $14.855,770000$ \\
\hline 0351 & Log Normal & 8,719645 & 2,194422 \\
\hline 0378 & Log Normal & 9,437439 & 1,877550 \\
\hline 0520 & Weibull & 1,163465 & $33.468,830000$ \\
\hline 0531 & Log Normal & 8,576584 & 1,180336 \\
\hline 0542 & Pareto & 1,823012 & $22.083,000000$ \\
\hline 0553 & Log Normal & 8,847384 & 1,364390 \\
\hline 0622 & Log Normal & 7,107324 & 2,287613 \\
\hline 0776 & Weibull & 0,687407 & $44.799,860000$ \\
\hline 0929 & Log Normal & 8,171670 & 1,481832 \\
\hline 0982 & Weibull & 0,575525 & $27.042,790000$ \\
\hline 0993 & Weibull & 0,531372 & $35.212,310000$ \\
\hline 1061 & Exponencial & 0,000003 & - \\
\hline 1065 & Exponencial & 0,000025 & - \\
\hline 1107 & Log Normal & 11,239290 & 2,099462 \\
\hline 1108 & Weibull & 1,870992 & $348.268,600000$ \\
\hline 1130 & Pareto & 1,324501 & $13.649,750000$ \\
\hline 1162 & Log Normal & 9,188282 & 1,510290 \\
\hline 1369 & Log Normal & 7,492330 & 1,220113 \\
\hline 1381 & Weibull & 0,603155 & $13.780,910000$ \\
\hline 1391 & Weibull & 0,592405 & $88.280,090000$ \\
\hline 1433 & Log Normal & 10,534710 & 1,490059 \\
\hline
\end{tabular}

Nota. Distribuição paramétrica ajustada ao padrão de severidade de cada ramo Susep para os sinistros observados entre jan/2015 e maio/2018. Fonte: elaborado pelos autores, a partir dos microdados cedidos por uma seguradora.

Conforme a Tabela 3, o procedimento de simulação foi absolutamente capaz de reproduzir os padrôes de ocorrências. Praticamente em todos os ramos a frequência, a severidade e o $\mathrm{S}_{A g}$ ficaram próximos dos números reais. Para os ramos em que isto não se verificou, tais como 0115 , 0141, 0378 ou 0929, a justificativa da subestimação reside no fato de que existe um, dois ou, no máximo, três sinistros que destoam completamente da média. Como mais de 98\% dos valores estão próximos da média observada, as distribuiçóes escolhidas ponderam este fato e não geram outliers de tamanha magnitude. 
Tabela 3. Comparativo dos resultados das 10 mil simulaçóes geradas.

\begin{tabular}{|c|c|c|c|c|c|c|c|c|c|c|}
\hline $\begin{array}{l}\text { Ramo } \\
\text { SUSEP }\end{array}$ & $\begin{array}{l}\text { Quantidade } \\
\text { real de } \\
\text { sinistros }\end{array}$ & $\begin{array}{l}\text { Severidade } \\
\text { real média }\end{array}$ & $\begin{array}{l}\text { Desvio- } \\
\text {-padráo da } \\
\text { severidade } \\
\text { real }\end{array}$ & $\begin{array}{c}\text { Sinistro } \\
\text { agregado real }\end{array}$ & $\begin{array}{l}\text { Quantidade } \\
\text { simulada de } \\
\text { sinistros }\end{array}$ & $\begin{array}{c}\text { Desvio- } \\
\text {-padrão da } \\
\text { quantidade } \\
\text { simulada de } \\
\text { sinistros }\end{array}$ & $\begin{array}{l}\text { Severidade } \\
\text { média } \\
\text { simulada }\end{array}$ & $\begin{array}{l}\text { Desvio- } \\
\text {-padrão da } \\
\text { severidade } \\
\text { simulada }\end{array}$ & $\begin{array}{l}\text { Sinistro agregado } \\
\text { simulado }\end{array}$ & $\begin{array}{c}\text { Desvio-padrão } \\
\text { do sinistro } \\
\text { agregado } \\
\text { simulado }\end{array}$ \\
\hline 0114 & 3.665 & 3.170 & 6.219 & 11.304 .497 & 3.664 & 60 & 3.068 & 71 & 11.241 .646 & 321.511 \\
\hline 0115 & 1.724 & 14.144 & 153.754 & 23.691 .684 & 1.724 & 42 & 9.993 & 851 & 17.224 .825 & 1.526 .160 \\
\hline 0116 & 15.497 & 7.774 & 37.514 & 115.973 .402 & 15.498 & 124 & 8.623 & 264 & 133.631 .878 & 4.226 .332 \\
\hline 0118 & 9.368 & 13.423 & 112.225 & 123.317 .872 & 9.368 & 97 & 10.226 & 681 & 95.801 .861 & 6.465 .361 \\
\hline 0141 & 149 & 55.914 & 235.608 & 8.051 .606 & 148 & 12 & 36.315 & 14.726 & 5.363 .731 & 2.211 .263 \\
\hline 0167 & 129 & 100.087 & 348.572 & 12.410 .834 & 129 & 11 & 86.632 & 26.583 & 11.157 .005 & 3.565 .402 \\
\hline 0171 & 1.522 & 69.905 & 175.689 & 102.341 .011 & 1.522 & 39 & 83.879 & 6.994 & 127.645 .585 & 11.145 .762 \\
\hline 0196 & 226 & 1.985 .611 & 15.971 .559 & 395.136 .599 & 225 & 15 & 2.313 .002 & 1.203 .446 & 519.986 .423 & 272.772 .749 \\
\hline 0310 & 32 & 145.214 & 225.743 & 3.194 .702 & 31 & 6 & 89.235 & 34.347 & 2.756 .309 & 1.152 .132 \\
\hline 0351 & 1.123 & 76.978 & 415.125 & 78.209 .877 & 1.123 & 34 & 63.111 & 10.664 & 70.877 .974 & 12.167 .670 \\
\hline 0378 & 195 & 82.091 & 300.082 & 9.933 .014 & 195 & 14 & 67.262 & 16.443 & 13.121 .638 & 3.346 .181 \\
\hline 0520 & 15.445 & 31.725 & 29.325 & 480.245 .649 & 15.445 & 124 & 31.743 & 221 & 490.292 .785 & 5.248 .623 \\
\hline 0531 & 209.931 & 10.535 & 18.919 & 2.094 .995 .096 & 209.925 & 451 & 10.648 & 40 & 2.235 .261 .496 & 9.717 .617 \\
\hline 0542 & 113 & 23.195 & 33.311 & 2.528 .304 & 112 & 11 & 22.246 & 3.399 & 2.496 .865 & 450.023 \\
\hline 0553 & 1.989 & 19.437 & 55.375 & 36.833 .542 & 1.989 & 44 & 17.618 & 902 & 35.046 .728 & 1.960 .556 \\
\hline 0622 & 28 & 10.265 & 21.634 & 215.570 & 28 & 5 & 7.765 & 3.769 & 214.409 & 110.012 \\
\hline 0776 & 18 & 54.233 & 57.041 & 921.957 & 18 & 4 & 51.057 & 15.954 & 909.918 & 351.544 \\
\hline 0929 & 24 & 14.408 & 39.268 & 345.787 & 24 & 5 & 10.148 & 4.641 & 243.210 & 118.570 \\
\hline 0982 & 69 & 42.926 & 74.669 & 2.833 .139 & 69 & 8 & 41.755 & 8.682 & 2.875 .300 & 685.610 \\
\hline 0993 & 279 & 64.837 & 145.872 & 17.181 .765 & 279 & 17 & 63.143 & 7.741 & 17.609 .584 & 2.379 .540 \\
\hline 1061 & 19 & 380.745 & 457.635 & 7.234 .153 & 19 & 4 & 380.539 & 89.980 & 7.200 .097 & 2.366 .969 \\
\hline 1065 & 12 & 40.799 & 47.816 & 489.587 & 12 & 3 & 40.598 & 12.331 & 487.979 & 200.162 \\
\hline 1107 & 37 & 368.361 & 640.511 & 12.892 .629 & 36 & 6 & 351.766 & 130.853 & 12.756 .151 & 5.126 .124 \\
\hline 1108 & 11 & 309.346 & 179.427 & 3.402 .804 & 11 & 3 & 308.670 & 54.199 & 3.398 .395 & 1.162 .105 \\
\hline 1130 & 2.052 & 31.989 & 83.250 & 63.753 .243 & 2.050 & 46 & 31.899 & 2.217 & 65.388 .380 & 4.746 .168 \\
\hline 1162 & 1.310 & 30.467 & 82.954 & 38.388 .106 & 1.310 & 36 & 30.331 & 2.226 & 39.730 .908 & 3.109 .557 \\
\hline 1369 & 8.578 & 4.352 & 14.203 & 29.768 .255 & 8.578 & 92 & 3.775 & 76 & 32.381 .395 & 729.853 \\
\hline 1381 & 80 & 20.321 & 34.979 & 1.442 .772 & 80 & 9 & 20.462 & 3.946 & 1.637 .020 & 365.818 \\
\hline 1391 & 85 & 143.205 & 297.613 & 11.886 .047 & 85 & 9 & 134.649 & 26.161 & 11.431 .826 & 2.521 .761 \\
\hline 1433 & 252 & 122.024 & 352.286 & 27.577 .383 & 252 & 16 & 111.985 & 17.288 & 28.214 .144 & 4.667 .516 \\
\hline
\end{tabular}

Nota. Da segunda à quinta coluna, são apresentados os valores efetivamente observados na base de dados por ramo Susep; da sexta à nona coluna, são apresentados os resultados das simulaçôes. As duas últimas colunas trazem os resultados das convoluçôes (entre frequência e severidade) para cada ramo. Fonte: elaborado pelos autores, a partir dos microdados cedidos por uma seguradora.

\section{RESULTADOS E DISCUSSÕES}

\section{Cenário-base}

Tanto para o cenário-base (processo de risco de Cramér-Lundberg sem a incorporação de resseguro) como para os cenários modificados, simularam-se 100 mil trajetórias temporais, de maneira a observar em quantas destas o $U_{t}$ da Equação (2) tornou-se estritamente menor que zero. Ademais, como a quantidade de apólices e frequência de sinistros referem-se a três anos de operação, as 100 mil trajetórias consideraram 70 períodos de evolução, o que significam 210 anos de desenvolvimento no tempo. Esta quantidade de períodos foi definida tendo em vista a expectativa considerada aceitável pelo Solvency II: uma ruína a cada 200 anos $(0,5 \%)$. 
Tomaram-se como premissas: (a) carteiras estáveis, em que entradas e saídas estão equilibradas e com mesmo padrão, para todos os ramos; (b) o percentual de inadimplência é igual a zero; e (c) a arrecadação de prêmios é constante em cada período e igual à quantidade de apólices vezes o prêmio médio calculado. $\mathrm{O} S_{A g}$ de cada período foi obtido por meio de uma escolha aleatória do vetor de $10 \mathrm{mil}$ cenários possíveis mencionado na subseção 'As estatísticas descritivas e o ajuste das distribuiçóes de sinistros'

A Tabela 4 traz a probabilidade de ruína estimada no cenário-base (sem resseguro) para cada ramo, em funçáo de diferentes valores do capital de solvência $\left(U_{0}\right)$, com o objetivo de avaliar a sua sensibilidade a variações de diferentes definiçôes da reserva inicial.

Tabela 4. Probabilidade de ruína (em \%) estimada por ramo Susep e capital de solvência.

\begin{tabular}{|c|c|c|c|c|c|c|c|c|c|c|c|c|c|}
\hline \multirow[b]{2}{*}{ Ramo } & \multicolumn{13}{|c|}{ Capital de solvência $^{(1)}$} \\
\hline & 0 & 500 & 1.000 & 1.500 & 2.000 & 2.500 & 3.000 & 3.500 & 4.000 & 4.500 & 5.000 & 5.500 & 6.000 \\
\hline 0114 & 0,0 & 0,0 & 0,0 & 0,0 & 0,0 & 0,0 & 0,0 & 0,0 & 0,0 & 0,0 & 0,0 & 0,0 & 0,0 \\
\hline 0115 & 0,1 & 0,0 & 0,0 & 0,0 & 0,0 & 0,0 & 0,0 & 0,0 & 0,0 & 0,0 & 0,0 & 0,0 & 0,0 \\
\hline 0116 & 0,0 & 0,0 & 0,0 & 0,0 & 0,0 & 0,0 & 0,0 & 0,0 & 0,0 & 0,0 & 0,0 & 0,0 & 0,0 \\
\hline 0118 & 0,0 & 0,0 & 0,0 & 0,0 & 0,0 & 0,0 & 0,0 & 0,0 & 0,0 & 0,0 & 0,0 & 0,0 & 0,0 \\
\hline 0141 & 0,0 & 0,0 & 0,0 & 0,0 & 0,0 & 0,0 & 0,0 & 0,0 & 0,0 & 0,0 & 0,0 & 0,0 & 0,0 \\
\hline 0167 & 0,3 & 0,2 & 0,1 & 0,1 & 0,1 & 0,0 & 0,0 & 0,0 & 0,0 & 0,0 & 0,0 & 0,0 & 0,0 \\
\hline 0171 & 8,6 & 7,8 & 7,4 & 6,9 & 6,7 & 6,1 & 5,5 & 5,1 & 4,7 & 4,4 & 3,9 & 3,7 & 3,5 \\
\hline 0196 & 100 & 100 & 100 & 100 & 100 & 100 & 100 & 100 & 100 & 100 & 100 & 100 & 100 \\
\hline 0310 & 0,0 & 0,0 & 0,0 & 0,0 & 0,0 & 0,0 & 0,0 & 0,0 & 0,0 & 0,0 & 0,0 & 0,0 & 0,0 \\
\hline 0351 & 0,0 & 0,0 & 0,0 & 0,0 & 0,0 & 0,0 & 0,0 & 0,0 & 0,0 & 0,0 & 0,0 & 0,0 & 0,0 \\
\hline 0378 & 0,0 & 0,0 & 0,0 & 0,0 & 0,0 & 0,0 & 0,0 & 0,0 & 0,0 & 0,0 & 0,0 & 0,0 & 0,0 \\
\hline 0520 & 100 & 100 & 100 & 100 & 100 & 100 & 100 & 100 & 100 & 100 & 100 & 100 & 100 \\
\hline 0531 & 0,0 & 0,0 & 0,0 & 0,0 & 0,0 & 0,0 & 0,0 & 0,0 & 0,0 & 0,0 & 0,0 & 0,0 & 0,0 \\
\hline 0542 & 0,0 & 0,0 & 0,0 & 0,0 & 0,0 & 0,0 & 0,0 & 0,0 & 0,0 & 0,0 & 0,0 & 0,0 & 0,0 \\
\hline 0553 & 0,0 & 0,0 & 0,0 & 0,0 & 0,0 & 0,0 & 0,0 & 0,0 & 0,0 & 0,0 & 0,0 & 0,0 & 0,0 \\
\hline 0622 & 0,0 & 0,0 & 0,0 & 0,0 & 0,0 & 0,0 & 0,0 & 0,0 & 0,0 & 0,0 & 0,0 & 0,0 & 0,0 \\
\hline 0776 & 0,0 & 0,0 & 0,0 & 0,0 & 0,0 & 0,0 & 0,0 & 0,0 & 0,0 & 0,0 & 0,0 & 0,0 & 0,0 \\
\hline 0929 & 35,1 & 1,3 & 0,0 & 0,0 & 0,0 & 0,0 & 0,0 & 0,0 & 0,0 & 0,0 & 0,0 & 0,0 & 0,0 \\
\hline 0982 & 0,0 & 0,0 & 0,0 & 0,0 & 0,0 & 0,0 & 0,0 & 0,0 & 0,0 & 0,0 & 0,0 & 0,0 & 0,0 \\
\hline 0993 & 6,6 & 4,6 & 3,1 & 2,0 & 1,3 & 0,8 & 0,6 & 0,3 & 0,2 & 0,1 & 0,0 & 0,0 & 0,0 \\
\hline 1061 & 0,0 & 0,0 & 0,0 & 0,0 & 0,0 & 0,0 & 0,0 & 0,0 & 0,0 & 0,0 & 0,0 & 0,0 & 0,0 \\
\hline 1065 & 0,0 & 0,0 & 0,0 & 0,0 & 0,0 & 0,0 & 0,0 & 0,0 & 0,0 & 0,0 & 0,0 & 0,0 & 0,0 \\
\hline 1107 & 3,4 & 2,9 & 2,4 & 2,0 & 1,8 & 1,5 & 1,2 & 1,0 & 0,9 & 0,8 & 0,6 & 0,5 & 0,5 \\
\hline 1108 & 100 & 100 & 100 & 100 & 100 & 100 & 100 & 100 & 100 & 100 & 100 & 100 & 100 \\
\hline 1130 & 13,1 & 11,5 & 9,5 & 8,3 & 7,0 & 6,1 & 5,1 & 4,1 & 3,5 & 2,9 & 2,4 & 2,0 & 1,6 \\
\hline 1162 & 0,0 & 0,0 & 0,0 & 0,0 & 0,0 & 0,0 & 0,0 & 0,0 & 0,0 & 0,0 & 0,0 & 0,0 & 0,0 \\
\hline 1369 & 0,0 & 0,0 & 0,0 & 0,0 & 0,0 & 0,0 & 0,0 & 0,0 & 0,0 & 0,0 & 0,0 & 0,0 & 0,0 \\
\hline 1381 & 80,7 & 57,3 & 39,3 & 26,5 & 17,7 & 11,6 & 7,5 & 4,8 & 3,0 & 1,9 & 1,1 & 0,7 & 0,4 \\
\hline 1391 & 9,1 & 6,9 & 5,2 & 3,8 & 2,7 & 2,1 & 1,4 & 1,0 & 0,7 & 0,5 & 0,4 & 0,2 & 0,2 \\
\hline 1433 & 30,2 & 27,3 & 24,4 & 22,1 & 19,8 & 18,0 & 16,1 & 14,1 & 12,7 & 11,0 & 10,0 & 8,7 & 7,8 \\
\hline
\end{tabular}

Nota. As probabilidades de ruína (em \%) foram estimadas para cada ramo a partir das 100.000 simulaçóes de Monte Carlo do processo de risco de Cramér-Lundberg, para diferentes níveis de capital de solvência, sem resseguro. ${ }^{(1)} \mathrm{em} R$ \$ 1.000,00. Fonte: elaborado pelos autores, a partir dos resultados das simulaçóes. 
A primeira conclusão que a Tabela 4 proporciona é a de que cada ramo possui uma dinâmica própria. Observa-se que diversos ramos apresentam percentuais de ruína próximos de zero (dentre os quais encontram-se importantes ramos como 0118, 0310, 0531, 0553, 1061) mesmo sem capital de solvência, enquanto outros têm reduções significativas com aumentos da reserva inicial (0171, 0929, 0993, 1130, 1381, entre outros). No extremo oposto, alguns relevantes ramos $(0196,0520$ e 1108) continuam com $100 \%$ de ruína esperada ou próximos deste nível, mesmo com elevados volumes de capital de solvência. Esta ruína (quase) certa tem como justificativa principal o fato de que os sinistros destes ramos possuem elevados patamares de resseguro, evitando, justamente, que estes cenários de insolvência se materializem (o ramo 0196, por exemplo, pela Tabela 1 possui o sinistro com maior severidade da base de dados - cerca de 211 milhóes de reais).

Ainda, a ruína (quase) certa do ramo 0520 e o percentual próximo de zero do 0531 podem ser um indício de que há um subsídio cruzado, de forma que as coberturas oferecidas encontram-se juntas no momento de emissão das apólices, o que possibilitaria ao prêmio excedente do 0531 oxigenar o resultado do 0520 . Já para o ramo 1108 , uma possível explicação seria a própria lógica de sua construção, uma vez que contém cobertura do Fundo de Estabilidade do Seguro Rural (FESR), que possui como objetivo manter e garantir o equilíbrio das operaçóes agrícolas no país, bem como atender à cobertura suplementar dos riscos de catástrofe, inerentes à atividade rural.

Assim, as sociedades seguradoras recuperam do FESR, no seguro florestas, a parcela de seus sinistros retidos compreendidos entre $100 \%$ e $150 \%$ de sinistralidade, assim como os montantes que excedam $250 \%$ de sinistralidade. Ou seja, exemplificando para um sinistro, já líquido dos mecanismos de resseguro, caso este, individualmente, ainda ultrapasse $100 \%$ de sinistralidade, os valores incorridos pela seguradora que compóem o excesso aos $100 \%$ poderão ser recuperados via FESR, limitados a 150\%. Entre 150\% e $250 \%$ de sinistralidade, o ônus da severidade do sinistro volta a ser integralmente da seguradora, porém, após ultrapassar $250 \%$, há novamente o direito de recuperação por meio do FESR.

\section{Com resseguro proporcional}

Para este cenário, promoveu-se a inserção de um tratado de resseguro proporcional do tipo quota-parte, transformando a variável aleatória original - vide a Equação (1). Assim, simulou-se o processo de risco com dois diferentes percentuais de retenção $(\alpha)$, aplicados diretamente tanto na arrecadaçáo dos prêmios como nos montantes de sinistro agregado. Os percentuais de retenção definidos no estudo foram de $90 \%$ e $80 \%$, respectivamente, sendo a escolha por estes patamares baseada estritamente nos dispostos da Política de Riscos da seguradora que forneceu os dados, bem como em seu painel de resseguro praticado no exercício de 2018 . O procedimento adotado para a escolha dos percentuais visa a atribuir autenticidade ao trabalho, uma vez que as cessóes assumidas estáo em linha com as práticas atuais do regulador.

Como é possível notar pela comparação das Tabelas 4 e 5, a imposiçáo de um tratado de resseguro proporcional do tipo quota-parte, devido ao seu próprio desenho, permite à seguradora reduzir a incerteza de seus resultados e, consequentemente, diminuir a probabilidade de ruína para um mesmo nível de reserva inicial. Ainda, quando se confronta o mecanismo de transferência de riscos com diferentes pesos de retenção, fica evidente que a redução do $\alpha$ contratual intensifica o decaimento da probabilidade de ruína estimada para zero. Como exemplo, a Figura 1 traz a comparação da sensibilidade do funcional para o ramo 0171.

Entretanto, cabe ressaltar que para os ramos apontados como mais desequilibrados na subseção 'Cenário-base' (tais como 0196, 0520, 1108 e 1381), a presença do resseguro proporcional náo se mostrou suficiente para tornar o ramo solvente per se. Esta evidência é parcialmente explicada pelo fato de que, independentemente do percentual de retenção definido, ainda assim os sinistros de extrema severidade acarretarão dispêndios elevados à seguradora, uma vez que o ônus da materializaçáo do risco coberto incidirá nas partes envolvidas (seguradora e resseguradora) na proporção do repasse do prêmio. Desta maneira, em praticamente todas as simulaçóes, os prêmios retidos em certo instante de tempo são integralmente consumidos pelos sinistros de cauda, assim como a reserva de solvência inicialmente estabelecida.

\section{Com resseguro não proporcional}

Para este cenário, considerou-se a imposiçáo de um tratado de resseguro não proporcional do tipo ED, conforme a Equação (1). Assim, para cada sinistro simulado, por ramo e por simulação (10 mil cenários de sinistro agregado), promoveu-se uma verificaçáo do montante individual de severidade, de forma que se este montante superasse a prioridade do ramo, entáo o seu valor deixaria de ser o originalmente simulado, passando a assumir o valor da prioridade. Ou seja, a severidade individual dos sinistros simulados foi truncada pela prioridade do ramo, uma vez que se avalia a perspectiva da seguradora, e o excesso torna-se de responsabilidade da resseguradora. 
Tabela 5. Probabilidade de ruína estimada (em \%) por ramo Susep e capital de solvência - quota-parte com a = 90\%.

\begin{tabular}{|c|c|c|c|c|c|c|c|c|c|c|c|c|c|}
\hline \multirow[b]{2}{*}{ Ramo } & \multicolumn{13}{|c|}{ Capital de solvência ${ }^{(1)}$} \\
\hline & 0 & 500 & 1.000 & 1.500 & 2.000 & 2.500 & 3.000 & 3.500 & 4.000 & 4.500 & 5.000 & 5.500 & 6.000 \\
\hline 0114 & 0,0 & 0,0 & 0,0 & 0,0 & 0,0 & 0,0 & 0,0 & 0,0 & 0,0 & 0,0 & 0,0 & 0,0 & 0,0 \\
\hline 0115 & 0,1 & 0,0 & 0,0 & 0,0 & 0,0 & 0,0 & 0,0 & 0,0 & 0,0 & 0,0 & 0,0 & 0,0 & 0,0 \\
\hline 0116 & 0,0 & 0,0 & 0,0 & 0,0 & 0,0 & 0,0 & 0,0 & 0,0 & 0,0 & 0,0 & 0,0 & 0,0 & 0,0 \\
\hline 0118 & 0,0 & 0,0 & 0,0 & 0,0 & 0,0 & 0,0 & 0,0 & 0,0 & 0,0 & 0,0 & 0,0 & 0,0 & 0,0 \\
\hline 0141 & 0,0 & 0,0 & 0,0 & 0,0 & 0,0 & 0,0 & 0,0 & 0,0 & 0,0 & 0,0 & 0,0 & 0,0 & 0,0 \\
\hline 0167 & 0,3 & 0,2 & 0,2 & 0,1 & 0,1 & 0,1 & 0,0 & 0,1 & 0,0 & 0,0 & 0,0 & 0,0 & 0,0 \\
\hline 0171 & 8,1 & 7,6 & 6,9 & 6,3 & 5,8 & 5,3 & 5,0 & 4,6 & 4,2 & 3,7 & 3,4 & 3,0 & 2,8 \\
\hline 0196 & 100 & 100 & 100 & 100 & 100 & 100 & 100 & 100 & 100 & 100 & 100 & 100 & 100 \\
\hline 0310 & 0,0 & 0,0 & 0,0 & 0,0 & 0,0 & 0,0 & 0,0 & 0,0 & 0,0 & 0,0 & 0,0 & 0,0 & 0,0 \\
\hline 0351 & 0,0 & 0,0 & 0,0 & 0,0 & 0,0 & 0,0 & 0,0 & 0,0 & 0,0 & 0,0 & 0,0 & 0,0 & 0,0 \\
\hline 0378 & 0,0 & 0,0 & 0,0 & 0,0 & 0,0 & 0,0 & 0,0 & 0,0 & 0,0 & 0,0 & 0,0 & 0,0 & 0,0 \\
\hline 0520 & 100 & 100 & 100 & 100 & 100 & 100 & 100 & 100 & 100 & 100 & 100 & 100 & 100 \\
\hline 0531 & 0,0 & 0,0 & 0,0 & 0,0 & 0,0 & 0,0 & 0,0 & 0,0 & 0,0 & 0,0 & 0,0 & 0,0 & 0,0 \\
\hline 0542 & 0,0 & 0,0 & 0,0 & 0,0 & 0,0 & 0,0 & 0,0 & 0,0 & 0,0 & 0,0 & 0,0 & 0,0 & 0,0 \\
\hline 0553 & 0,0 & 0,0 & 0,0 & 0,0 & 0,0 & 0,0 & 0,0 & 0,0 & 0,0 & 0,0 & 0,0 & 0,0 & 0,0 \\
\hline 0622 & 0,0 & 0,0 & 0,0 & 0,0 & 0,0 & 0,0 & 0,0 & 0,0 & 0,0 & 0,0 & 0,0 & 0,0 & 0,0 \\
\hline 0776 & 0,0 & 0,0 & 0,0 & 0,0 & 0,0 & 0,0 & 0,0 & 0,0 & 0,0 & 0,0 & 0,0 & 0,0 & 0,0 \\
\hline 0929 & 34,9 & 0,8 & 0,0 & 0,0 & 0,0 & 0,0 & 0,0 & 0,0 & 0,0 & 0,0 & 0,0 & 0,0 & 0,0 \\
\hline 0982 & 0,0 & 0,0 & 0,0 & 0,0 & 0,0 & 0,0 & 0,0 & 0,0 & 0,0 & 0,0 & 0,0 & 0,0 & 0,0 \\
\hline 0993 & 7,0 & 4,6 & 3,1 & 2,0 & 1,2 & 0,7 & 0,4 & 0,3 & 0,1 & 0,1 & 0,1 & 0,0 & 0,0 \\
\hline 1061 & 0,0 & 0,0 & 0,0 & 0,0 & 0,0 & 0,0 & 0,0 & 0,0 & 0,0 & 0,0 & 0,0 & 0,0 & 0,0 \\
\hline 1065 & 0,0 & 0,0 & 0,0 & 0,0 & 0,0 & 0,0 & 0,0 & 0,0 & 0,0 & 0,0 & 0,0 & 0,0 & 0,0 \\
\hline 1107 & 3,4 & 2,9 & 2,4 & 1,9 & 1,5 & 1,3 & 1,0 & 0,8 & 0,7 & 0,6 & 0,5 & 0,4 & 0,4 \\
\hline 1108 & 100 & 100 & 100 & 100 & 100 & 100 & 100 & 100 & 100 & 100 & 100 & 100 & 100 \\
\hline 1130 & 13,9 & 11,9 & 10,1 & 8,4 & 7,1 & 5,9 & 5,0 & 4,0 & 3,4 & 2,7 & 2,0 & 1,7 & 1,3 \\
\hline 1162 & 0,0 & 0,0 & 0,0 & 0,0 & 0,0 & 0,0 & 0,0 & 0,0 & 0,0 & 0,0 & 0,0 & 0,0 & 0,0 \\
\hline 1369 & 0,0 & 0,0 & 0,0 & 0,0 & 0,0 & 0,0 & 0,0 & 0,0 & 0,0 & 0,0 & 0,0 & 0,0 & 0,0 \\
\hline 1381 & 81,0 & 54,8 & 35,2 & 22,6 & 14,0 & 8,8 & 5,1 & 3,0 & 1,8 & 1,1 & 0,6 & 0,3 & 0,2 \\
\hline 1391 & 10,3 & 7,8 & 5,2 & 3,7 & 2,7 & 1,8 & 1,3 & 1,0 & 0,6 & 0,4 & 0,3 & 0,2 & 0,2 \\
\hline 1433 & 29,3 & 26,4 & 23,2 & 20,5 & 18,2 & 16,1 & 13,9 & 12,7 & 10,9 & 9,7 & 8,3 & 7,3 & 6,5 \\
\hline
\end{tabular}

Nota. as probabilidades de ruína (em \%) foram estimadas para cada ramo a partir das 100.000 simulaçóes de Monte Carlo do processo de risco de Cramér-Lundberg, para diferentes níveis de capital de solvência, com resseguro quota-parte $(\alpha=90 \%)$. ${ }^{(1)}$ em $\mathrm{R} \$ 1.000,00$. Fonte: elaborado pelos autores, a partir dos resultados das simulaçóes. 
Tabela 6. Probabilidade de ruína estimada (em \%) por ramo Susep e capital de solvência - quota-parte com a = 80\%.

\begin{tabular}{|c|c|c|c|c|c|c|c|c|c|c|c|c|c|}
\hline \multicolumn{14}{|c|}{ Capital de solvência ${ }^{(1)}$} \\
\hline Ramo & 0 & 500 & 1.000 & 1.500 & 2.000 & 2.500 & 3.000 & 3.500 & 4.000 & 4.500 & 5.000 & 5.500 & 6.000 \\
\hline 0114 & 0,0 & 0,0 & 0,0 & 0,0 & 0,0 & 0,0 & 0,0 & 0,0 & 0,0 & 0,0 & 0,0 & 0,0 & 0,0 \\
\hline 0115 & 0,1 & 0,0 & 0,0 & 0,0 & 0,0 & 0,0 & 0,0 & 0,0 & 0,0 & 0,0 & 0,0 & 0,0 & 0,0 \\
\hline 0116 & 0,0 & 0,0 & 0,0 & 0,0 & 0,0 & 0,0 & 0,0 & 0,0 & 0,0 & 0,0 & 0,0 & 0,0 & 0,0 \\
\hline 0118 & 0,0 & 0,0 & 0,0 & 0,0 & 0,0 & 0,0 & 0,0 & 0,0 & 0,0 & 0,0 & 0,0 & 0,0 & 0,0 \\
\hline 0141 & 0,0 & 0,0 & 0,0 & 0,0 & 0,0 & 0,0 & 0,0 & 0,0 & 0,0 & 0,0 & 0,0 & 0,0 & 0,0 \\
\hline 0167 & 0,3 & 0,2 & 0,1 & 0,1 & 0,1 & 0,1 & 0,1 & 0,0 & 0,0 & 0,0 & 0,0 & 0,0 & 0,0 \\
\hline 0171 & 8,1 & 7,3 & 6,8 & 6,2 & 5,7 & 5,2 & 4,6 & 4,3 & 3,7 & 3,4 & 2,9 & 2,6 & 2,4 \\
\hline 0196 & 100 & 100 & 100 & 100 & 100 & 100 & 100 & 100 & 100 & 100 & 100 & 100 & 100 \\
\hline 0310 & 0,0 & 0,0 & 0,0 & 0,0 & 0,0 & 0,0 & 0,0 & 0,0 & 0,0 & 0,0 & 0,0 & 0,0 & 0,0 \\
\hline 0351 & 0,0 & 0,0 & 0,0 & 0,0 & 0,0 & 0,0 & 0,0 & 0,0 & 0,0 & 0,0 & 0,0 & 0,0 & 0,0 \\
\hline 0378 & 0,0 & 0,0 & 0,0 & 0,0 & 0,0 & 0,0 & 0,0 & 0,0 & 0,0 & 0,0 & 0,0 & 0,0 & 0,0 \\
\hline 0520 & 100 & 100 & 100 & 100 & 100 & 100 & 100 & 100 & 100 & 100 & 100 & 100 & 100 \\
\hline 0531 & 0,0 & 0,0 & 0,0 & 0,0 & 0,0 & 0,0 & 0,0 & 0,0 & 0,0 & 0,0 & 0,0 & 0,0 & 0,0 \\
\hline 0542 & 0,0 & 0,0 & 0,0 & 0,0 & 0,0 & 0,0 & 0,0 & 0,0 & 0,0 & 0,0 & 0,0 & 0,0 & 0,0 \\
\hline 0553 & 0,0 & 0,0 & 0,0 & 0,0 & 0,0 & 0,0 & 0,0 & 0,0 & 0,0 & 0,0 & 0,0 & 0,0 & 0,0 \\
\hline 0622 & 0,0 & 0,0 & 0,0 & 0,0 & 0,0 & 0,0 & 0,0 & 0,0 & 0,0 & 0,0 & 0,0 & 0,0 & 0,0 \\
\hline 0776 & 0,0 & 0,0 & 0,0 & 0,0 & 0,0 & 0,0 & 0,0 & 0,0 & 0,0 & 0,0 & 0,0 & 0,0 & 0,0 \\
\hline 0929 & 34,9 & 0,5 & 0,0 & 0,0 & 0,0 & 0,0 & 0,0 & 0,0 & 0,0 & 0,0 & 0,0 & 0,0 & 0,0 \\
\hline 0982 & 0,0 & 0,0 & 0,0 & 0,0 & 0,0 & 0,0 & 0,0 & 0,0 & 0,0 & 0,0 & 0,0 & 0,0 & 0,0 \\
\hline 0993 & 6,9 & 4,4 & 2,8 & 1,6 & 1,0 & 0,5 & 0,3 & 0,1 & 0,1 & 0,1 & 0,0 & 0,0 & 0,0 \\
\hline 1061 & 0,0 & 0,0 & 0,0 & 0,0 & 0,0 & 0,0 & 0,0 & 0,0 & 0,0 & 0,0 & 0,0 & 0,0 & 0,0 \\
\hline 1065 & 0,0 & 0,0 & 0,0 & 0,0 & 0,0 & 0,0 & 0,0 & 0,0 & 0,0 & 0,0 & 0,0 & 0,0 & 0,0 \\
\hline 1107 & 3,6 & 2,7 & 2,2 & 1,7 & 1,4 & 1,1 & 1,0 & 0,7 & 0,6 & 0,5 & 0,4 & 0,3 & 0,3 \\
\hline 1108 & 100 & 100 & 100 & 100 & 100 & 100 & 100 & 100 & 100 & 100 & 100 & 100 & 100 \\
\hline 1130 & 13,9 & 11,5 & 9,6 & 7,9 & 6,5 & 5,2 & 4,3 & 3,5 & 2,7 & 2,0 & 1,6 & 1,3 & 1,0 \\
\hline 1162 & 0,0 & 0,0 & 0,0 & 0,0 & 0,0 & 0,0 & 0,0 & 0,0 & 0,0 & 0,0 & 0,0 & 0,0 & 0,0 \\
\hline 1369 & 0,0 & 0,0 & 0,0 & 0,0 & 0,0 & 0,0 & 0,0 & 0,0 & 0,0 & 0,0 & 0,0 & 0,0 & 0,0 \\
\hline 1381 & 81,1 & 51,8 & 31,6 & 18,9 & 11,1 & 6,4 & 3,5 & 1,9 & 1,0 & 0,6 & 0,3 & 0,1 & 0,0 \\
\hline 1391 & 10,1 & 7,2 & 5,1 & 3,4 & 2,2 & 1,5 & 1,1 & 0,7 & 0,5 & 0,3 & 0,2 & 0,2 & 0,1 \\
\hline 1433 & 29,2 & 25,7 & 22,6 & 19,6 & 16,7 & 14,9 & 12,8 & 11,4 & 9,7 & 8,3 & 7,2 & 6,1 & 5,3 \\
\hline
\end{tabular}

Nota. As probabilidades de ruína (em \%) foram estimadas para cada ramo a partir das 100.000 simulaçóes de Monte Carlo do processo de risco de Cramér-Lundberg, para diferentes níveis de capital de solvência, com resseguro quota-parte $(\alpha=80 \%) .{ }^{(1)} \mathrm{em} R \$ 1.000,00$. Fonte: elaborado pelos autores, a partir dos resultados das simulaçóes.

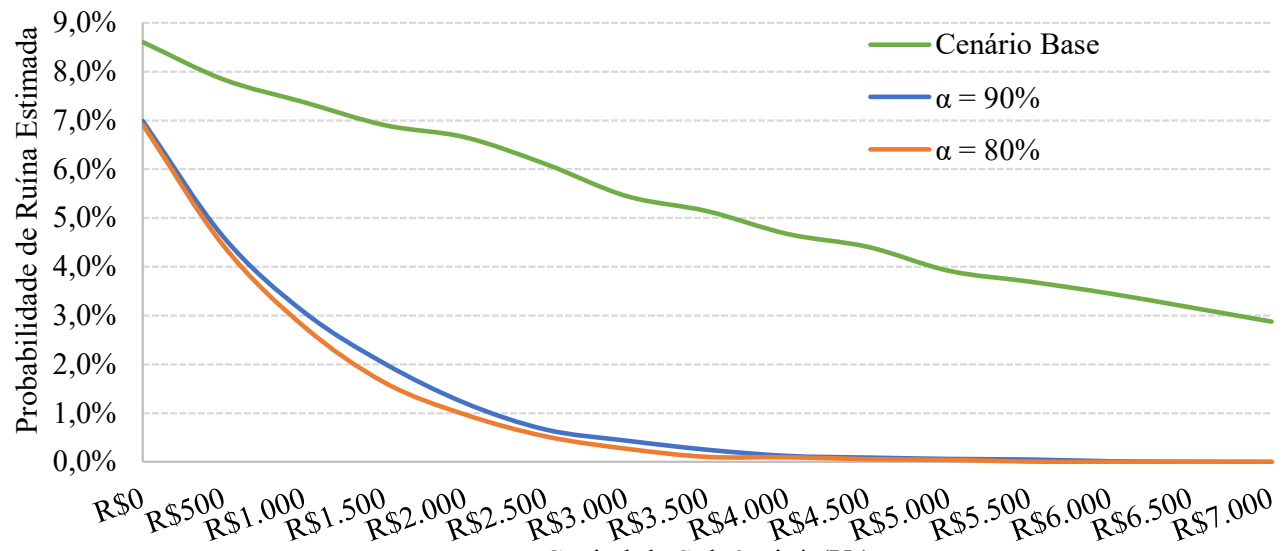

Capital de Solvência* $\left(\mathrm{U}_{0}\right)$

Figura 1. Probabilidade de ruína estimada - comparativo dos cenários para o ramo 0171.

* Os valores de capital de solvência estáo expressos em R \$ 1.000,00. Fonte: elaborado pelos autores. 
Inicialmente, a escolha da prioridade, por ramo, foi feita tendo em vista o LR informado na plataforma oficial SESSusep, posição de ago/2018. Todavia, apurou-se que o histórico de sinistros, em sua maioria, não continha severidades que excediam os LR informados. Assim, assumiram-se os valores da extração como prioridade do contrato de resseguro somente para os ramos cuja suposição fazia-se cabível. Estes ramos estáo detalhados na Tabela 7.

Para os demais, elaborou-se uma análise para verificar qual deveria ser a prioridade considerada para o ramo, transferindo à resseguradora aproximadamente a mesma proporção dos ramos cuja escolha do limite deu-se por meio do SES-Susep.

Tabela 7. Descritivo da prioridade considerada (em R\$).

\begin{tabular}{|c|c|c|c|c|}
\hline Ramo Susep & Descrição do ramo & Severidade máxima real & Limite de retenção informado & $\begin{array}{l}\text { Prioridade considerada para o } \\
\text { excesso de danos }\end{array}$ \\
\hline 0114 & Compreensivo Residencial & 133.009 & 10.000 .000 & 66.000 \\
\hline 0115 & Roubo & 5.528 .754 & 10.000 .000 & 2.700 .000 \\
\hline 0116 & Compreensivo Condomínio & 3.416 .440 & 10.000 .000 & 1.700 .000 \\
\hline 0118 & Compreensivo Empresarial & 6.639 .786 & 10.000 .000 & 3.300 .000 \\
\hline 0141 & Lucros Cessantes & 1.464 .188 & 10.000 .000 & 700.000 \\
\hline 0167 & Riscos de Engenharia & 2.910 .709 & 10.000 .000 & 1.500 .000 \\
\hline 0171 & Riscos Diversos & 3.372 .572 & 10.000 .000 & 1.700 .000 \\
\hline 0196 & $\mathrm{RN}$ e RO & 211.148 .985 & 10.000 .000 & 10.000 .000 \\
\hline 0310 & $\mathrm{D} \& \mathrm{O}$ & 725.332 & 2.000 .000 & 360.000 \\
\hline 0351 & R. C. Geral & 9.132 .978 & 2.000 .000 & 2.000 .000 \\
\hline 0378 & R. C. Profissional & 3.002 .375 & 2.000 .000 & 2.000 .000 \\
\hline 0520 & APP & 578.717 & 1.910 .938 & 22.000 \\
\hline 0531 & Automóvel - Casco & 1.373 .636 & 1.910 .938 & 680.000 \\
\hline 0542 & Assistência e Outras Cobert. & 172.602 & 1.910 .938 & 85.000 \\
\hline 0553 & RCFV & 1.313 .308 & 3.500 .000 & 650.000 \\
\hline 0622 & Transporte Internacional & 90.062 & 4.000 .000 & 44.000 \\
\hline 0776 & Garantia Segurado - Privado & 180.500 & 5.000 .000 & 90.000 \\
\hline 0929 & Seguro Funeral & 190.966 & 1.500 .000 & 95.000 \\
\hline 0982 & AP - Coletivo & 346.454 & 1.910 .938 & 170.000 \\
\hline 0993 & Vida - Pessoas Coletivo & 1.294 .180 & 1.910 .938 & 641.000 \\
\hline 1061 & Habitacional - Prestamista & 1.858 .775 & 5.000 .000 & 920.000 \\
\hline 1065 & Habitacional - Demais & 171.917 & 10.000 .000 & 85.000 \\
\hline 1107 & Florestas sem FESR & 3.144 .258 & 3.000 .000 & 3.000 .000 \\
\hline 1108 & Florestas com FESR & 603.246 & 3.000 .000 & 75.000 \\
\hline 1130 & Benfeitorias e Prod. Agropec. & 1.275 .627 & 10.000 .000 & 630.000 \\
\hline 1162 & Penhor Rural & 1.693 .228 & 10.000 .000 & 840.000 \\
\hline 1369 & Viagem & 590.423 & 1.910 .938 & 290.000 \\
\hline 1381 & $\mathrm{AP}$ - Individual & 239.264 & 1.910 .938 & 118.000 \\
\hline 1391 & Vida - Pessoas Individual & 2.053 .441 & 1.910 .938 & 1.910 .938 \\
\hline 1433 & Marítimos (Casco) & 3.782 .900 & 2.000 .000 & 2.000 .000 \\
\hline
\end{tabular}

Nota. A tabela traz um comparativo entre a maior severidade (em R \$) observada na base de dados e o limite de retenção (prioridade) informado pela seguradora à Susep. Esta prioridade legal foi utilizada para impor um limiar de transferência de risco para a resseguradora. Para os ramos Susep em que todas as severidades observadas estavam abaixo da prioridade definida, optou-se por transferir à resseguradora a mesma proporção dos ramos cuja escolha do limite deu-se por meio do SES-Susep. Fonte: elaborado pelos autores, a partir da base de dados e do SES-Susep. 
Tabela 8. Probabilidade de ruína estimada (em \%) por ramo Susep e capital de solvência - excesso de danos.

\begin{tabular}{|c|c|c|c|c|c|c|c|c|c|c|c|c|c|}
\hline \multirow[b]{2}{*}{ Ramo } & \multicolumn{13}{|c|}{ Capital de solvência ${ }^{(1)}$} \\
\hline & 0 & 500 & 1.000 & 1.500 & 2.000 & 2.500 & 3.000 & 3.500 & 4.000 & 4.500 & 5.000 & 5.500 & 6.000 \\
\hline 0114 & 0,0 & 0,0 & 0,0 & 0,0 & 0,0 & 0,0 & 0,0 & 0,0 & 0,0 & 0,0 & 0,0 & 0,0 & 0,0 \\
\hline 0115 & 0,0 & 0,0 & 0,0 & 0,0 & 0,0 & 0,0 & 0,0 & 0,0 & 0,0 & 0,0 & 0,0 & 0,0 & 0,0 \\
\hline 0116 & 0,0 & 0,0 & 0,0 & 0,0 & 0,0 & 0,0 & 0,0 & 0,0 & 0,0 & 0,0 & 0,0 & 0,0 & 0,0 \\
\hline 0118 & 0,0 & 0,0 & 0,0 & 0,0 & 0,0 & 0,0 & 0,0 & 0,0 & 0,0 & 0,0 & 0,0 & 0,0 & 0,0 \\
\hline 0141 & 0,0 & 0,0 & 0,0 & 0,0 & 0,0 & 0,0 & 0,0 & 0,0 & 0,0 & 0,0 & 0,0 & 0,0 & 0,0 \\
\hline 0167 & 0,0 & 0,0 & 0,0 & 0,0 & 0,0 & 0,0 & 0,0 & 0,0 & 0,0 & 0,0 & 0,0 & 0,0 & 0,0 \\
\hline 0171 & 0,0 & 0,0 & 0,0 & 0,0 & 0,0 & 0,0 & 0,0 & 0,0 & 0,0 & 0,0 & 0,0 & 0,0 & 0,0 \\
\hline 0196 & 0,0 & 0,0 & 0,0 & 0,0 & 0,0 & 0,0 & 0,0 & 0,0 & 0,0 & 0,0 & 0,0 & 0,0 & 0,0 \\
\hline 0310 & 0,0 & 0,0 & 0,0 & 0,0 & 0,0 & 0,0 & 0,0 & 0,0 & 0,0 & 0,0 & 0,0 & 0,0 & 0,0 \\
\hline 0351 & 0,0 & 0,0 & 0,0 & 0,0 & 0,0 & 0,0 & 0,0 & 0,0 & 0,0 & 0,0 & 0,0 & 0,0 & 0,0 \\
\hline 0378 & 0,0 & 0,0 & 0,0 & 0,0 & 0,0 & 0,0 & 0,0 & 0,0 & 0,0 & 0,0 & 0,0 & 0,0 & 0,0 \\
\hline 0520 & 43,4 & 36,3 & 30,4 & 24,7 & 20,0 & 16,1 & 12,6 & 9,8 & 7,8 & 6,1 & 4,8 & 3,8 & 3,0 \\
\hline 0531 & 0,0 & 0,0 & 0,0 & 0,0 & 0,0 & 0,0 & 0,0 & 0,0 & 0,0 & 0,0 & 0,0 & 0,0 & 0,0 \\
\hline 0542 & 0,0 & 0,0 & 0,0 & 0,0 & 0,0 & 0,0 & 0,0 & 0,0 & 0,0 & 0,0 & 0,0 & 0,0 & 0,0 \\
\hline 0553 & 0,0 & 0,0 & 0,0 & 0,0 & 0,0 & 0,0 & 0,0 & 0,0 & 0,0 & 0,0 & 0,0 & 0,0 & 0,0 \\
\hline 0622 & 0,0 & 0,0 & 0,0 & 0,0 & 0,0 & 0,0 & 0,0 & 0,0 & 0,0 & 0,0 & 0,0 & 0,0 & 0,0 \\
\hline 0776 & 0,0 & 0,0 & 0,0 & 0,0 & 0,0 & 0,0 & 0,0 & 0,0 & 0,0 & 0,0 & 0,0 & 0,0 & 0,0 \\
\hline 0929 & 11,6 & 0,1 & 0,0 & 0,0 & 0,0 & 0,0 & 0,0 & 0,0 & 0,0 & 0,0 & 0,0 & 0,0 & 0,0 \\
\hline 0982 & 0,0 & 0,0 & 0,0 & 0,0 & 0,0 & 0,0 & 0,0 & 0,0 & 0,0 & 0,0 & 0,0 & 0,0 & 0,0 \\
\hline 0993 & 0,0 & 0,0 & 0,0 & 0,0 & 0,0 & 0,0 & 0,0 & 0,0 & 0,0 & 0,0 & 0,0 & 0,0 & 0,0 \\
\hline 1061 & 0,0 & 0,0 & 0,0 & 0,0 & 0,0 & 0,0 & 0,0 & 0,0 & 0,0 & 0,0 & 0,0 & 0,0 & 0,0 \\
\hline 1065 & 0,0 & 0,0 & 0,0 & 0,0 & 0,0 & 0,0 & 0,0 & 0,0 & 0,0 & 0,0 & 0,0 & 0,0 & 0,0 \\
\hline 1107 & 0,0 & 0,0 & 0,0 & 0,0 & 0,0 & 0,0 & 0,0 & 0,0 & 0,0 & 0,0 & 0,0 & 0,0 & 0,0 \\
\hline 1108 & 76,1 & 39,6 & 19,6 & 9,3 & 4,2 & 2,0 & 0,9 & 0,4 & 0,1 & 0,1 & 0,0 & 0,0 & 0,0 \\
\hline 1130 & 0,0 & 0,0 & 0,0 & 0,0 & 0,0 & 0,0 & 0,0 & 0,0 & 0,0 & 0,0 & 0,0 & 0,0 & 0,0 \\
\hline 1162 & 0,0 & 0,0 & 0,0 & 0,0 & 0,0 & 0,0 & 0,0 & 0,0 & 0,0 & 0,0 & 0,0 & 0,0 & 0,0 \\
\hline 1369 & 0,0 & 0,0 & 0,0 & 0,0 & 0,0 & 0,0 & 0,0 & 0,0 & 0,0 & 0,0 & 0,0 & 0,0 & 0,0 \\
\hline 1381 & 9,6 & 1,0 & 0,1 & 0,0 & 0,0 & 0,0 & 0,0 & 0,0 & 0,0 & 0,0 & 0,0 & 0,0 & 0,0 \\
\hline 1391 & 0,2 & 0,1 & 0,1 & 0,0 & 0,0 & 0,0 & 0,0 & 0,0 & 0,0 & 0,0 & 0,0 & 0,0 & 0,0 \\
\hline 1433 & 0,0 & 0,0 & 0,0 & 0,0 & 0,0 & 0,0 & 0,0 & 0,0 & 0,0 & 0,0 & 0,0 & 0,0 & 0,0 \\
\hline
\end{tabular}

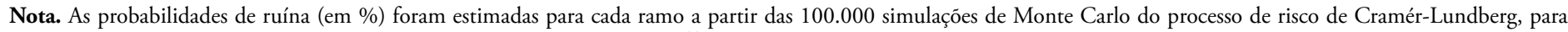
diferentes níveis de capital de solvência, com resseguro de excesso de danos. ${ }^{(1)}$ em $\mathrm{R} \$ 1.000,00$. Fonte: elaborado pelos autores, a partir dos resultados das simulaçóes.

A partir da Tabela 8, é possível observar que o ramo 0196, que antes apresentava percentuais de ruína próximos de $100 \%$, agora, mesmo sem reserva inicial, revela-se perto de zero. Isto acontece porque há em seu histórico real de sinistros apenas uma observação cujo resultado de subscrição desequilibra a carteira. Assim, no momento das simulaçóes, a constituição de um ou mais sinistros de tamanha severidade é suficiente para levar a entidade à falência. Portanto, quando se limita a perda máxima da seguradora no montante da prioridade estabelecida (neste caso igual a $\mathrm{R} \$ 10$ milhóes), verifica-se que os prêmios retidos são suficientes para manter a solvência durante o desenvolvimento do processo de risco. Os ramos 1108, 1381 e 1391 também apresentam reduções expressivas em suas estimativas de ruína, além de demonstrarem extrema sensibilidade frente a variaçóes de diferentes definiçóes da reserva inicial.

Conforme resultado trazido pela Tabela 4, parece haver indícios de que os ramos 0520 e 0531 possuam algum tipo de subsídio cruzado. Esse fenômeno pode ocorrer desde a estruturaçáo dos produtos, tendo em vista que as 
coberturas de Acidentes Pessoais de Passageiros (0520) e Automóvel - Casco (0531) costumam ser oferecidas em conjunto na cobertura básica oferecida pelas seguradoras. Ainda, existe respaldo legal (parágrafo $8^{\circ}$ do artigo $2^{\circ}$ do anexo XXVII da resoluçáo CNSP n.o 321/2015) que permite às seguradoras desenvolver metodologias atuariais agregadas de precificação e avaliação de reservas, desde que as entidades sejam capazes de demonstrar, por meio de justificativa técnica, algum critério de similaridade entre os ramos agrupados (homogeneidade de fatores de risco).

Portanto, a probabilidade de ruína de 3,0\% do ramo 0520 para um elevado capital de solvência $(\mathrm{R} \$$ $6.000 .000,00)$, na verdade, estaria superdimensionada, uma vez que o prêmio excedente do ramo 0531 (com ruína esperada de $0 \%$ desde $\mathrm{R} \$ 0,00$ de capital de solvência) auxiliaria na manutenção do equilíbrio da carteira.

Ademais, é importante frisar que a efetividade do resseguro não proporcional está diretamente associada a uma escolha correta da prioridade. No caso de uma definição equivocada, de um lado, o prêmio retido será reduzido devido ao repasse à resseguradora de uma parcela do prêmio total, enquanto do outro, os sinistros incorridos não terão recuperações de resseguro, uma vez que suas severidades individuais não alcançam a prioridade contratual. Desta maneira, o objetivo de blindar o resultado da companhia náo é alcançado. Pelo contrário: aumenta-se a exposição do ramo a um possível cenário de insolvência, realidade que talvez náo se verificasse sem a implementação do resseguro.

A Figura 2 traz, como exemplo, o ramo 1381. A Figura 2 exemplifica duas importantes conclusóes: (a) formato exponencial do decaimento da probabilidade de ruína estimada a partir de aumentos consecutivos do capital de solvência; e (b) que a adoçáo de um contrato de resseguro adequado às características do ramo possibilita deslocamento da curva de estimativas de ruína, haja vista a queda do percentual inicial de $80 \%$ para $10 \%$.

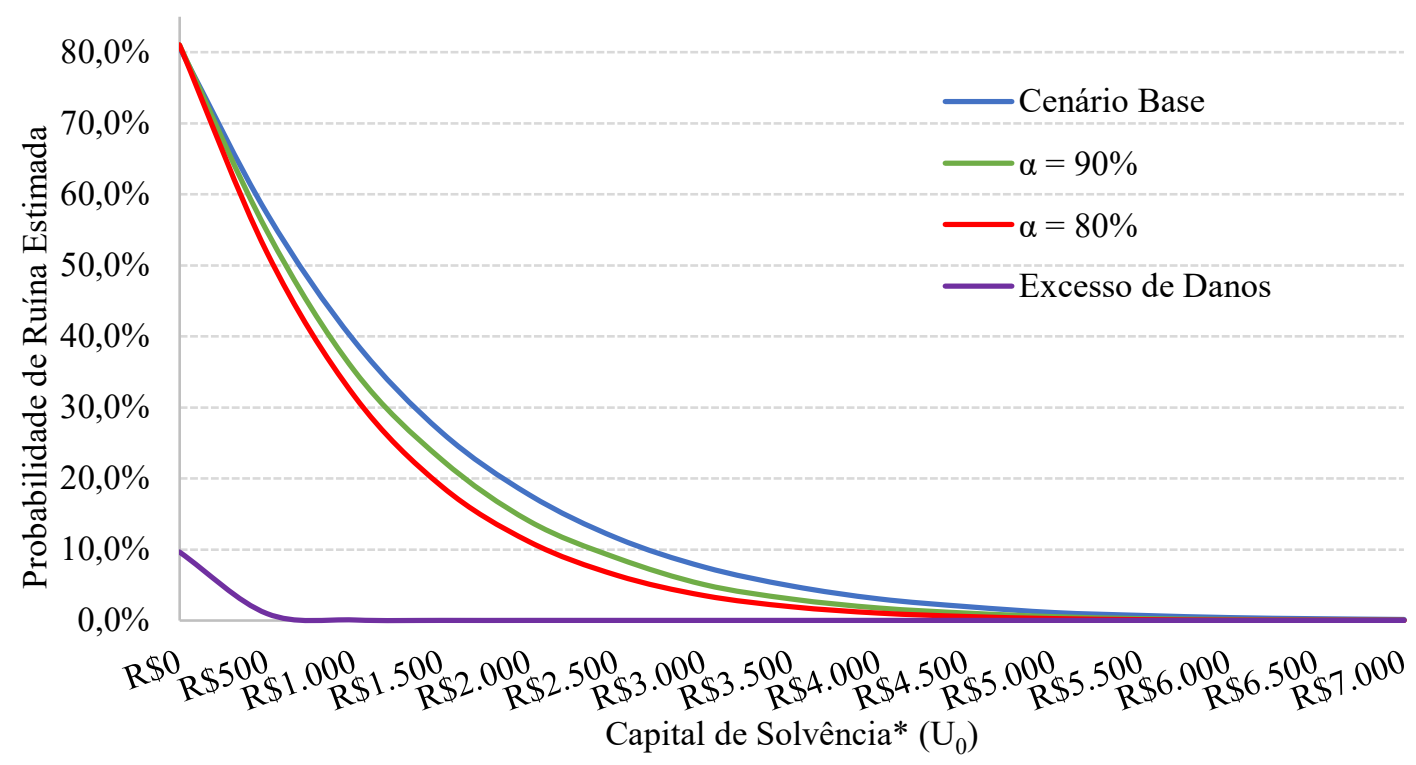

Figura 2. Probabilidade de ruína estimada - comparativo dos cenários para o ramo 1381.

* Os valores de capital de solvência estáo expressos em R\$1.000,00. Fonte: elaborado pelos autores.

\section{CONSIDERAÇÕES FINAIS}

Neste trabalho, buscou-se estimar a probabilidade de ruína de uma entidade seguradora ao incorporar contratos de resseguro, comparando ao cenário-base em que as operaçóes gerenciais de receitas e despesas ocorrem sem modificaçóes em suas variáveis aleatórias. $\mathrm{Na}$ literatura são escassos os trabalhos que propuseram aplicaçóes diretas do processo de risco a microdados, incorporando, ainda, estruturas de resseguro e entendendo seus efeitos nas estimativas de falência. Como consequência, pôde-se dimensionar o capital de solvência associado a riscos de subscrição, bem como analisar os seus efeitos na redução da probabilidade de ruína.

Para obter estimativas precisas, a metodologia aqui desenvolvida pautou-se em recursos computacionais que executaram rotinas via MMC. Assim, o trabalho foi 
estruturado em quatro etapas: extraçáo e validação da base de dados com histórico de sinistros reais, seguidas pelo ajuste das distribuiçóes probabilísticas, por ramo Susep. Depois, simularam-se 10 mil cenários de sinistro agregado, para cada ramo, visando a medir a capacidade de geração de observaçóes fidedignas dos sinistros reais. Com isto, variaram-se três cenários de processos de risco, em que foram simuladas 100 mil trajetórias temporais, desenvolvidas, cada uma, por 210 anos.

Finalmente, foi possível observar o decaimento exponencial na relação entre a probabilidade de ruína a aumentos no capital de solvência, sendo esta sensibilidade intensificada por meio da adoção de contratos de resseguro. Ademais, para um mesmo nível de reserva inicial, a probabilidade de ruína é menor com um tratado de ED comparativamente a uma quota-parte, desde que calibrada a prioridade contratual. Por isso, é imprescindível que seja feita uma análise minuciosa e técnica no momento da escolha do painel de resseguros, visando a assegurar a convergência das expectativas de redução da volatilidade da

\section{REFERÊNCIAS}

Afonso, L. B., Cardoso, R. M. R., Reis, A. D. E. dos, \& Guerreiro, G. R. (2017). Measuring the impact of a bonus-malus system in finite and continuous time ruin probabilities for large portfolios in motor insurance. ASTIN Bulletin, 47(2), 417-435. https://doi.org/10.1017/asb.2017.3

Albrecher, H., \& Haas, S. (2011). Ruin theory with excess of loss reinsurance and reinstatements. Applied Mathematics and Computation, 217(20), 8031-8043. https://doi.org/10.1016/j.amc.2011.02.109

Bareche, A., \& Cherfaoui, M. (2019). Sensitivity of the stability bound for ruin probabilities to claim distributions. Methodology and Computing in Applied Probability, 21(4), 1259-1281. https://doi.org/10.1007/s11009-018-9675-7 operaçáo e de medidas gerenciais de risco com os resultados reais observados nas carteiras.

Por simplificação, não foram considerados fatores intrínsecos à operação de uma seguradora, tais como: rendimentos de investimentos, distribuição de dividendos, despesas administrativas e reconhecimento contábil por regime de competência, constituindo a principal limitação deste estudo. Da mesma maneira, náo foram abordadas as parcelas de CBR de crédito, operacional e de mercado. Não obstante, a importância deste estudo é reforçada pelo advento das normas contábeis internacionais. O IFRS 17, que substituirá o IFRS 4 e passará a vigorar em 2023, acentuará ainda mais a indispensabilidade da mensuração do capital de solvência e outras quantidades (England, Verrall, \& Wüthrich, 2019; Moro \& Krvavych, 2017). Logo, as metodologias internas deverão ser capazes de incorporar todos os mecanismos de transferência de risco, analisando conjuntamente os valores brutos e líquidos, além de explicitar para os gestores e stakeholders os efeitos que estas ferramentas promovem na solvência de longo prazo.
Baumgartner, B., \& Gatto, R. (2010). A bootstrap test for the probability of ruin in the compound poisson risk process. ASTIN Bulletin, 40(1), 241-255. https://doi.org/10.2143/AST.40.1.2049227

Bowers, N. L., Gerber, H. U., Hickman, J. C., Jones, D. A., \& Nesbitt, C. J. (1997). Actuarial mathematics (2nd ed.). Schaumburg, IL: The Society of Actuaries.

Charpentier, A. (2010). Reinsurance, ruin and solvency issues: Some pitfalls [Working Paper hal00463381]. HAL Archives-Ouvertes. Retrieved from https://hal.archives-ouvertes.fr/hal-00463381/document

Chen, Y., \& Yuan, Z. (2017). A revisit to ruin probabilities in the presence of heavy-tailed insurance and financial risks. Insurance: Mathematics and Economics, 73, 75-81. https://doi.org/10.1016/j.insmatheco.2017.01.005 
Cheng,J.,Gao,Y., \&Wang,D.(2016).Ruin probabilitiesforaperturbed risk model with stochastic premiums and constant interest force. Journal of Inequalities and Applications, 2016(1), 214. https://doi.org/10.1186/s13660-016-1135-8

Cheung, E. C. K., Dai, S., \& Ni, W. (2018). Ruin probabilities in a Sparre Andersen model with dependency structure based on a threshold window. Annals of Actuarial Science, 12(2), 269-295. https://doi.org/10.1017/S1748499517000215

Constantinescu, C. D., Kozubowski, T. J., \& Qian, H. H. (2019). Probability of ruin in discrete insurance risk model with dependent Pareto claims. Dependence Modeling, 7(1), 215-233. https://doi.org/10.1515/demo-2019-0011

Coulibaly, I., \& Lefèvre, C. (2008). On a simple quasi-Monte Carlo approach for classical ultimate ruin probabilities. Insurance: Mathematics and Economics, 42(3), 935-942. https://doi.org/10.1016/j.insmatheco.2007.10.008

Deelstra,G., \&Plantin,G.(2014).Risktheoryandreinsurance.London: Springer. https://doi.org/10.1007/978-1-4471-5568-3

Dickson, D. C. M., \& Qazvini, M. (2016). Gerber-Shiu analysis of a risk model with capital injections. European Actuarial Journal, 6(2), 409-440. https://doi.org/10.1007/s13385-016-0131-1

Dong, Y., \& Wang, D. (2018). Uniform asymptotics for ruin probabilities in a two-dimensional nonstandard renewal risk model with stochastic returns. Journal of Inequalities and Applications, 2018(1), 319. https://doi.org/10.1186/s13660-018-1913-6

England, P. D., Verrall, R. J., \& Wüthrich, M. V. (2019). On the lifetime and one-year views of reserve risk, with application to IFRS 17 and Solvency II risk margins. Insurance: Mathematics and Economics, 85, 74-88. https://doi.org/10.1016/j.insmatheco.2018.12.002

Eryilmaz, S., \& Gebizlioglu, O. L. (2017). Computing finite time non-ruin probability and some joint distributions in discrete time risk model with exchangeable claim occurrences. Journal of Computational and Applied Mathematics, 313, 235-242. https://doi.org/10.1016/j.cam.2016.09.025

Gatto, R. (2020). The stability of the probability of ruin. Stochastic Models, 36(1), 112-133. https://doi.org/10.1080/15326349.2019.1695135

Gatto, R., \& Mosimann, M. (2012). Four approaches to compute the probability of ruin in the compound Poisson risk process with diffusion. Mathematical and Computer Modelling, 55(3-4), 1169-1185. https://doi.org/10.1016/j.mcm.2011.09.041

Lefèvre, C., Trufin, J., \& Zuyderhoff, P. (2017). Some comparison results for finite-time ruin probabilities in the classical risk model. Insurance: Mathematics and Economics, 77, 143149. https://doi.org/10.1016/j.insmatheco.2017.09.004
Lemos, S. R. R. (2008). Probabilidade da ruina no mercado de seguros: Fundamentos teóricos e alguns resultados de simulação (Master thesis). Universidade Federal de Pernambuco, Recife, PE, Brazil Retrieved from https://repositorio.ufpe.br/handle/123456789/6171

Melo, E. F. L. de. (2008). Uma aplicação de cópulas de Lévy na agregação de processos multivariados de ruína. Revista Brasileira de Risco e Seguro, 4(7), 47-64. Retrieved from http://www.rbrs.com.br/arquivos/RBRS7-3\%20 Eduardo\%20Fraga.pdf

Mikosch, T., \& Samorodnitsky, G. (2000). Ruin probability with claims modeled by a stationary ergodic stable process. Annals of Probability, 28(4), 1814-1851. https://doi.org/10.1214/aop/1019160509

Moro, E. D., \& Krvavych, Y. (2017). Probability of sufficiency of Solvency II reserve risk margins: Practical approximations. ASTIN Bulletin, 47(3), 737-785. https://doi.org/10.1017/asb.2017.12

Ramsden, L., \& Papaioannou, A. D. (2019). Ruin probabilities under capital constraints. Insurance: Mathematics and Economics, 88, 273-282. https://doi.org/10.1016/j.insmatheco.2018.11.002

Superintendência de Seguros Privados. (2018). 6o relatório de análise e acompanhamento dos mercados supervisionados. SUSEP. Rio de Janeiro, RJ, Brazil. Retrieved from http:// www.susep.gov.br/menuestatistica/SES/6b0\%20Relat Acomp Mercado 2018.pdf

Tamturk, M., \& Utev, S. (2018). Ruin probability via quantum mechanics approach. Insurance: Mathematics and Economics, 79, 69-74. https://doi.org/10.1016/j.insmatheco.2017.12.009

Touazi, A., Benouaret, Z., Aissani, D., \& Adjabi, S. (2017). Nonparametric estimation of the claim amount in the strong stability analysis of the classical risk model. Insurance: Mathematics and Economics, 74, 78-83. https://doi.org/10.1016/j.insmatheco.2017.02.007

Vidmar, M. (2018). Ruin under stochastic dependence between premium and claim arrivals. Scandinavian Actuarial Journal, 2018(6), 505-513. https://doi.org/10.1080/03461238.2017.1391114

Wüthrich, M. V. (2015). From ruin theory to solvency in non-life insurance. Scandinavian Actuarial Journal, 2015(6), 516526. https://doi.org/10.1080/03461238.2013.858401 


\section{Autoria}

\section{Jorge Wilson Euphasio Junior}

Universidade de Sáo Paulo, Faculdade de Economia, Administração, Contabilidade e Atuária

Av. Luciano Gualberto, no 908, Butantá, 05508-010, São Paulo, SP, Brasil.

E-mail: jorgeeuphasio@gmail.com

(1) https://orcid.org/0000-0003-3112-2281

\section{João Vinícius França Carvalho*}

Universidade de Sáo Paulo, Faculdade de Economia, Administração, Contabilidade e Atuária

Av. Luciano Gualberto, no 908, Butantã, 05508-010, São Paulo, SP, Brasil.

E-mail: jvfcarvalho@usp.br

(1) https://orcid.org/0000-0002-1076-662X

* Autor Correspondente

\section{Financiamento}

Os autores relataram que não houve suporte financeiro para pesquisa deste artigo.

\section{Conflito de Interesses}

Os autores informaram que não há conflito de interesses.

\section{Verificação de Plágio}

A RAC mantém a prática de submeter todos os documentos aprovados para publicação à verificação de plágio, mediante o emprego de ferramentas específicas, e.g.: iThenticate.

\section{Direitos Autorais}

A RAC detém os direitos autorais deste conteúdo.

\section{Contribuições dos Autores}

$1^{\text {a }}$ autor: curadoria de dados (igual); análise formal (igual); investigação (igual); software (igual); validação (igual); visualização (igual); escrita - rascunho original (igual); escrita - revisão e edição (igual).

$2^{\circ}$ autor: conceituação (liderança); curadoria de dados (igual); análise formal (igual); investigação (igual); metodologia (igual); administração de projeto (liderança); software (igual); supervisão (liderança); validação (igual); visualização (igual); escrita - rascunho original (igual); escrita - revisão e edição (igual).

\section{Método de Revisão por Pares}

Este conteúdo foi avaliado utilizando o processo de revisão por pares duplo-cego (double-blind peer-review). A divulgação das informaçóes dos pareceristas constantes na primeira página e do Relatório de Revisão por Pares (Peer Review Report) é feita somente após a conclusão do processo avaliativo, e com o consentimento voluntário dos respectivos pareceristas e autores.

\section{Disponibilidade dos Dados}

Os autores optaram por não compartilhar a sua base de dados, e afirmam que o fazem tendo em vista que um dos autores assinou um acordo de sigilo informacional com a entidade que gentilmente forneceu os dados apenas para o desenvolvimento da pesquisa. Este documento, com fé pública, devidamente assinado foi enviado à RAC como justificativa formal para o não compartilhamento dos dados. Os autores afirmam apoiar a política de Open Science promovida pela RAC em tudo o que está ao alcance legal.

A RAC incentiva o compartilhamento de dados mas, por observância a ditames éticos, não demanda a divulgação de qualquer meio de identificação de sujeitos de pesquisa, preservando a privacidade dos sujeitos de pesquisa. A prática de open data é viabilizar a reproducibilidade de resultados, e assegurar a irrestrita transparência dos resultados da pesquisa publicada, sem que seja demandada a identidade de sujeitos de pesquisa. 